\title{
CIEN AÑOS DE EMPRESAS PÚBLICAS EN URUGUAY: EVOLUCIÓN Y DESEMPEŃO
}

\author{
Magdalena Bertino \\ Universidad de la República, Uruguay \\ magda@iecon.ccee.edu.uy \\ Natalia Mariño \\ Universidad de la República, Uruguay \\ nataliam@iecon.ccee.edu.uy \\ Martina Querejeta \\ Universidad de la República, Uruguay \\ mquerejeta@iecon.ccee.edu.uy \\ Milton Torrelli \\ Universidad de la República, Uruguay \\ milton@iecon.ccee.edu.uy \\ Daniela VÁzQuez \\ Universidad de la República, Uruguay \\ dvazquez@iecon.ccee.edu.uy
}

\section{RESUMEN}

El trabajo se integra con dos miradas interrelacionadas sobre la evolución del Estado Empresario uruguayo a lo largo de su siglo de existencia. En una, se reconstruye en base a fuentes cualitativas dicha evolución identificando dos grandes etapas, coincidentes con los modelos de desarrollo por los que transitó el país y gran parte del mundo a partir de los años treinta. Durante la primera el Estado aumenta progresivamente sus funciones y se produce la expansión de las empresas públicas. En la segunda, desde los setenta, predominan políticas de corte neoliberal, se procura la reforma (o privatización) de las empresas en pos de mayor eficiencia y rentabilidad. Desde la otra perspectiva se analiza, en diálogo con dichas etapas, las series construidas sobre diferentes variables del desempeño de las principales empresas públicas no financieras (empleo, producción, productividad laboral, participación en el PIB y resultados financieros versus transferencias netas con el gobierno).

Palabras clave: Empresas públicas no financieras, Desempeño económicoproductivo, Productividad laboral, Uruguay. 


\title{
ONE HUNDRED YEARS OF PUBLIC COMPANIES IN URUGUAY: THEIR EVOLUTION AND PERFORMANCE
}

\begin{abstract}
This paper combines two interrelated approaches to examine the evolution of the state as entrepreneur in Uruguay over its century of existence. One of them uses qualitative sources to reconstruct its development, identifying two periods in this evolution; these coincide with the different development models that the country and the world have adopted since the Thirties. During the first one the state progressively expanded its functions and the expansion of public companies played an important role. Since the Seventies, a liberal model has predominated, based on the reform of the companies (or the privatization) placing more importance on efficiency and profitability. The second approach analyzes the time series of several important variables regarding the performance of the primary non-financial public companies (NFPC) (employment, production, labor productivity, value-added as a proportion of GDP and profit results versus net transfers from the government).
\end{abstract}

Keywords: Non-Financial Public Companies, Economic-Productive Performance, Uruguay. 


\section{INTRODUCCIÓN}

Más allá de los debates existentes en cuanto a los motivos y racionalidad económica de la intervención del Estado en la economía o su justificación, este trabajo presenta evidencia sobre las características de dicha intervención en lo que respecta al accionar del Estado como empresario. Son muchas las interrogantes pendientes al respecto, pero quizá la más importante sea la forma en que debe evaluarse la acción de las empresas públicas en la economía. La multiplicidad de objetivos perseguidos hace difícil evaluar su gestión a través de los criterios tradicionales de eficiencia utilizados para las empresas privadas. Estos objetivos pueden clasificarse en económicos, sociales y político-estratégicos, y su prioridad se ha definido según el modelo económico dominante y la coyuntura particular de cada período.

La evaluación de las empresas públicas puede abordarse desde tres dimensiones complementarias: la primera refiere a la eficiencia en el manejo de recursos, la segunda a la eficiencia en la consecución de los objetivos planteados y la tercera al grado de satisfacción de los usuarios. Esta investigación se concentra fundamentalmente en la primera, dejando planteada la necesidad de profundizar en las otras dos para lograr una visión más completa de la gestión y desempeño de estas empresas.

El trabajo se integra con dos miradas interrelacionadas sobre la evolución del Estado empresario uruguayo, con énfasis en las empresas públicas no financieras. La primera realiza una síntesis basada en fuentes cualitativas sobre dicha evolución identificando sus principales etapas, en la otra se analiza el desempeño de las principales empresas públicas no financieras uruguayas, en diálogo con las etapas identificadas y con las transitadas por la economía en su conjunto.

Por un lado, se reconstruye la evolución del conjunto de empresas públicas uruguayas a lo largo de un siglo, desde 1911-1912 cuando se crean o estatizan los tres grandes bancos públicos y la primera empresa pública no financiera, hasta la actualidad. La exposición se divide en dos grandes etapas, coincidentes con los dos modelos de desarrollo por los que transitó el país y, se podría afirmar, gran parte del mundo, a lo largo del siglo pasado: 1) un modelo basado en el desarrollo industrial, progresivamente dirigido por el Estado, en la construcción de Estados de bienestar y la expansión de las funciones sociales y económicas del Estado, en el se inscribe la fundación y la expansión de las empresas públicas, que llegaría hasta inicios de la década setenta; y 2) un segundo modelo que se caracteriza por la apertura económica, la creciente globalización, la desregulación económica y financiera, el avance del mercado sobre el Estado y la reducción de las funciones de éste. A nivel de las empresas 
públicas se tiende a modificar sus objetivos, dándose primacía a la lógica de la empresa privada basada en la rentabilidad y que, en los países donde este proceso es más fuerte, culmina con la privatización de las mismas.

Por otro lado, se analiza en primer lugar el desempeño económicoproductivo de las principales empresas públicas no financieras en el largo plazo, a partir del estudio del manejo del recurso capital humano (productividad laboral) y de la evidencia en cuanto al peso de su empleo en la Población Económicamente Activa (PEA) y de su generación de valor en el PIB. A continuación, se evalúa el desempeño económico-financiero a partir de los resultados obtenidos por dichas empresas y las trasferencias netas registradas con el gobierno central.

Las empresas públicas no financieras uruguayas (EPNF5 en este trabajo) consideradas son: Administración de los Ferrocarriles del Estado (AFE), Administración Nacional de Combustibles, Alcohol y Portland (ANCAP), Administración Nacional de Telecomunicaciones (ANTEL), Obras Sanitarias del Estado (OSE), que cubre el servicio de agua potable y el saneamiento (en este caso solo en el interior del país), y Administración de Usinas y Transmisiones Eléctricas (UTE). Ellas han sido las más importantes a lo largo del siglo XX por su tamaño y sectores de actuación, y las más perdurables, llegando en actividad hasta el momento actual ${ }^{1}$.

El documento se organiza de la siguiente forma: luego de esta introducción, en la segunda sección se definen las empresas públicas y se abordan algunos aspectos conceptuales de su estudio. En la tercera se recorren muy brevemente los principales antecedentes relevantes. En la cuarta sección se mencionan las fuentes de información utilizadas y las principales decisiones metodológicas adoptadas. En la quinta se recorren los modelos y etapas históricas de las empresas públicas uruguayas en general, para en la sexta sección presentar los resultados cuantitativos en materia de empleo, producción, productividad laboral, valor agregado, utilidades y transferencias netas con el gobierno central, para las principales empresas públicas no financieras en relación con dichas etapas. Finalmente, se presentan algunas reflexiones.

I Vale señalar que dentro de las principales empresas públicas seguramente debería incluirse en perspectiva histórica la Administración Nacional de Puertos (ANP) y la Administración Nacional de Correos. No obstante, en el primer caso no se cuenta con una serie de sus ingresos impidiendo así su tratamiento cuantitativo, y en el segundo, se trata de un ente descentralizado del gobierno central solo desde I997. 


\section{APUNTES CONCEPTUALES}

El estudio de las empresas públicas abunda en indefiniciones, tanto en lo que hace al concepto y sus límites, como en lo que atañe a la construcción de un modelo teórico para su estudio.

La Comisión Económica para América Latina (CEPAL) ha denominado empresa pública a aquella organización que combina los distintos factores de la producción, es decir, desarrolla una actividad empresarial para generar bienes o servicios, y cuya propiedad del capital y/o la administración es ejercida por el Estado. Estos bienes y servicios se venden en el mercado a precios significativos, es decir que cubren al menos una buena porción de sus costos (CEPAL 1983, en Bellini y Rougier 2008).

Esta definición enmarca sin dificultades a las grandes empresas públicas no financieras de Uruguay mencionadas previamente, que fueron fruto de decisiones tomadas por el Estado. Asimismo, caben en esta definición las tres grandes empresas bancarias totalmente estatales desde 1912: Banco de la República Oriental del Uruguay (BROU), Banco de Seguros del Estado (BSE) y Banco Hipotecario del Uruguay (BHU). Por otra parte, fueron escasas en Uruguay, especialmente si comparamos con el caso argentino, tanto las empresas mixtas como las empresas que pasaron a la administración del Estado por situaciones de quiebra o endeudamiento, limitándose éstas a algunos frigoríficos y una textil. También puede destacarse el caso muy particular de la Compañía del Gas, que mientras estuvo bajo propiedad estatal mantuvo sus funcionarios bajo la órbita del derecho privado.

Respecto a las dificultades para construir un modelo teórico, éstas se derivan de la complejidad intrínseca de la empresa pública, situada entre el gobierno central proveedor de bienes públicos y la empresa privada. A su vez, casi todos los estudios del tema destacan su complejidad por ser un ámbito de conjunción del juego político y el económico (Milnitsky 2001). Además, enfrenta el desafío de "entender" al mercado en el cual se inserta y al gobierno central que lo regula, controla e imprime objetivos de interés económico y social, enfrentando así objetivos de diversa índole y muchas veces cambiantes.

La multiplicidad de objetivos que tradicionalmente enfrentan las empresas públicas, hace que en muchos casos resulten contradictorios. Millward (2005) destaca que las empresas públicas fueron creadas para cumplir con dos objetivos: 1) defender el "interés público", asumir compromisos ligados a asuntos económicos, sociales y políticos fuera de la esfera de lo comercial; y 2) alcanzar el punto de equilibrio financiero, lo que implica que los ingresos de las empresas públicas deberían alcanzar para 
cubrir todos los egresos. Incluye entre los ingresos las subvenciones porque la meta financiera incluye explícitamente transferencias del gobierno para cumplir con los objetivos no comerciales.

Es necesario realizar algunas precisiones respecto de este último punto, dado que resulta discutible la incorporación de las subvenciones como parte de los ingresos de las empresas, y más en particular que los mismos sean resultado de un ejercicio consciente y calculado por parte del gobierno central. En el caso uruguayo, en general, no es claro el aporte económico del Estado a la consecución de objetivos no comerciales, dado que existe una serie de subsidios no explícitos -exoneración de impuestos por la vía de los hechos, asunciones de deudas por parte del gobierno central, deudas entre empresas públicas o con otros organismos estatales, entre otros- que habría que considerar de adoptar esta definición.

En este marco, las empresas públicas son un medio importante para la consecución de los objetivos de la política económica gubernamental y de las políticas públicas en general. En concreto, el caso uruguayo, estas empresas participan en varios frentes de la política económica, lo que acentúa la dificultad de su análisis. Sus tarifas tienen un rol importante en materia de inflación, así como de acceso a servicios básicos a costos accesibles, sus inversiones son parte de los programas de inversión pública de los gobiernos, su política salarial y de empleo impacta en la distribución del ingreso y en el mercado de trabajo, y sus resultados juegan en materia fiscal de forma no despreciable.

Finalmente, dado el objetivo de este trabajo interesa destacar lo que señala Millward respecto a que para estudiar la eficiencia de las empresas públicas no alcanza con observar lo sucedido con sus resultados, dado que la posición de monopolio y la supervisión, control y regulación de los gobiernos reducen su significación como indicador. Hay que estudiar también la utilización de los recursos para la producción. Las medidas tradicionalmente utilizadas para observar la eficiencia en la utilización de recursos son la productividad laboral o la productividad total de los factores. Lamentablemente, las limitaciones de información en cuanto al stock de capital de las empresas públicas no financieras imposibilita el estudio de esta última en este trabajo, limitándose al estudio de la productividad laboral.

\section{ANTECEDENTES}

En este apartado se mencionan solo los antecedentes, nacionales e internacionales, más relevantes en la elaboración del presente trabajo. 
En primer lugar, tres trabajos previos realizados por este mismo equipo de investigación son antecedentes directos retomados en parte en este artículo (Bertino et al. 2011, 2012a, 2012b). Por otro lado, se destacan los estudios de Boneo (1973), Solari y Franco (1983) y Nahum (1993), en tanto contribuyen a la comprensión del devenir histórico de las empresas públicas en Uruguay. Otros trabajos relevantes son: Piotti (1996), Carracelas et al. (2006), Nahum et al. (2006) y Bertino et al. (2012d), que brindan un análisis de la evolución de las principales empresas públicas no financieras nacionales (ANTEL, UTE, ANCAP y OSE, respectivamente).

También debe mencionarse el trabajo de Narbondo (2012), donde se estudian los cambios ocurridos en las empresas públicas no financieras durante los gobiernos del Frente Amplio desde 2005.

Entre los antecedentes internacionales utilizados se encuentran, por un lado, estudios realizados para las economías europeas (y estadounidense) como los de Comín y Díaz Fuentes (2004) y Millward (2005) y, por otro, trabajos como el de Del Campo y Winkler (1992), que se concentran en la implementación de las reformas de las empresas públicas y sus resultados en las economías latinoamericanas.

Cabe mencionar que no se encontraron antecedentes internacionales de estudio de la evolución del desempeño de empresas públicas como el aquí propuesto para períodos tan extensos, planteándose en general en la literatura sobre el tema la no disponibilidad de series de largo plazo que posibiliten análisis de este tipo.

\section{FUENTES DE INFORMACIÓN Y METODOLOGÍA}

Las fuentes principales para la reconstrucción de la evolución de las empresas públicas son las memorias y otras publicaciones de las empresas y el Registro de Leyes y Decretos. Se usaron además, otras fuentes secundarias como Acevedo (1919-1936) y Rodríguez López (1928).

Las fuentes de información para la reconstrucción de las series presentan gran diversidad. Gran parte del esfuerzo realizado en este trabajo fue dirigido a su análisis crítico y a su compatibilización y estimación en series continuas.

Para las series de desempeño económico-productivo (cantidades producidas de los productos más importantes, ingresos según principales productos y Valor Agregado Bruto), se utilizaron publicaciones de las empresas, de organismos públicos (Oficina de Planeamiento y Presupuesto, OPP, y Banco Central del Uruguay, BCU), y del Instituto de Economía. 
Para el empleo se revisaron y corrigieron parcialmente las series de funcionarios públicos de Azar et al. (2009).

Los índices agregados: Índice de Volumen Físico (IVF), Índice de Productividad Laboral (IPL) y Valor Agregado Bruto (VAB) se calcularon para cinco empresas públicas no financieras (AFE, ANCAP, ANTEL, OSE y UTE, anteriormente identificadas como EPNF5). Si bien las telecomunicaciones estuvieron en la órbita de UTE hasta la creación de ANTEL en 1974, con el fin de contar con series comparables para todo el período, dicha actividad se consideró separadamente de UTE, considerándose a ANTEL como la empresa telefónica desde inicio de los treinta.

Los IVF de las diferentes empresas públicas no financieras se construyeron utilizando ponderadores que reflejan la importancia relativa de cada producto dentro de la empresa (peso de su venta en los ingresos corrientes totales). De igual forma se construyó un IVF para el sector de EPNF5 $^{2}$. Los IPL se calcularon a partir de la relación entre el IVF y el nivel de empleo.

La productividad laboral pretende medir la relación entre la producción y la cantidad de trabajo incorporado, por esta razón sería deseable calcularla sobre la cantidad de horas trabajadas y no sobre la cantidad total de trabajadores, pero las limitaciones de información obligó a calcularla por la cantidad de funcionarios. Finalmente, cabe mencionar la limitación que introduce la construcción de un índice general a partir de índices expresados en diferentes unidades de medida, el hecho de no contar con una serie de VAB construida a partir de información de las empresas condujo a utilizar el IVF en el cálculo de la productividad laboral, por entenderlo como una mejor representación de la actividad de las empresas.

En cuanto a la información utilizada para el análisis económicofinanciero, las utilidades hasta 1946 surgen de las memorias de las empresas, Acevedo (1919-1936) y Rodríguez López (1928). Para las transferencias, las principales fuentes hasta los setenta fueron: Anuarios Estadísticos, Leyes y Decretos, Presupuestos Nacionales, Rendiciones de Cuentas, memorias de las empresas y Dondo (1942). A partir de 1973 la fuente prioritaria

2 Ponderar según el peso de productos o empresas en los ingresos corrientes, puede introducir distorsiones debido a que las distintas tarifas no evolucionan de la misma manera. A su vez, otras dos limitaciones de este tipo de agregación son: falta de datos de ingresos para algunas empresas públicas no financieras en ciertos períodos (sobre todo en los sesenta) que han debido estimarse y a que los ingresos de ANCAP, de gran peso en el total, no solo dependen de los precios internacionales del crudo, sino que incluyen importantes impuestos específicos a los combustibles que también inciden fuertemente y no han podido desagregarse. 
tanto de resultados como de transferencias fue OPP.

Un comentario final merece el período 1947-1972, donde no se cuenta con series de resultados, al tiempo que la información es escasa y fragmentada entre las distintas fuentes en materia de transferencias (en particular en los sesenta e inicio de los setenta). La información utilizada proviene principalmente de Leyes y Decretos, no contándose con otra fuente de chequeo sobre la aplicación efectiva de tal normativa.

\section{EVOLUCIÓN DE LAS EMPRESAS PÚBLICAS URUGUAYAS: MODELOS Y ETAPAS}

En el trabajo de Bertino et al. (2012a) se encuentra que en consonancia con la evolución de las empresas públicas en Europa (Comín y Díaz Fuentes 2004) y en Latinoamérica, se advierten dos grandes modelos de empresas públicas en el Uruguay del siglo XX, en los que se fundamenta la distinción de dos grandes períodos en la historia de las empresas públicas.

El primero se extiende desde la fundación de las primeras empresas a principio del siglo hasta inicios de los setenta. En su transcurso, en paralelo con el desarrollo de la industria, el cambio estructural y la progresiva implementación del Estado de bienestar, se expanden las funciones del Estado y el peso de las empresas públicas, se consolida la propiedad estatal de los servicios públicos y se pone el acento en sus objetivos sociales. El segundo, que se extiende hasta la actualidad, ha estado progresivamente permeado por la ideología liberal y la vuelta a una política liberal que había primado en el siglo XIX. Se entiende por esta política la promoción de la apertura externa y la liberalización comercial, la desregulación financiera, el avance del mercado y la reducción del tamaño del Estado y de las empresas públicas. Esta política se intensificó en los años noventa y comienzos del siglo XXI, pero fue confrontada en varios plebiscitos populares que se opusieron a la privatización de las empresas. Desde 2005, con la asunción de gobiernos frenteamplistas se detuvo en términos generales la orientación privatizadora, aunque se mantuvo como gran objetivo orientador la eficiencia económica y el autofinanciamiento.

\section{NACIMIENTO, EXPANSIÓN Y AUGE DEL ESTADO EMPRESARIO (1911-1973)}

Durante las primeras cinco décadas de existencia del Estado uruguayo que se inicia en 1828, el país vivió su primer período liberal, con un Estado débil, inmerso en guerras civiles. Los primeros servicios que se van formando se entregaban en concesión a privados: correo en el interior del país (1834), telégrafo (1868), teléfonos (1881), ferrocarriles (1865) y, en la capital, servicios de saneamiento (1857), agua corriente (1871) 
y electricidad (1884). En las últimas décadas del siglo XIX, el poder del Estado se fortalece y con él se desarrolla una mayor capacidad de regulación. Se promulga la primera ley regulatoria de ferrocarriles (1884), se crea la Dirección y Administración General de Correos (1877) y el Telégrafo Nacional (1977), que irá absorbiendo en las décadas siguientes a los telégrafos privados. A partir de la crisis bancaria de 1890 pasan al Estado las acciones de la Compañía de Electricidad y de algunas pequeñas líneas de ferrocarril. En 1896 se funda el Banco de la República (BROU), que funcionó desde el principio como banco estatal aunque se oficializó como tal en 1911.

\section{Surgimiento y consolidación de las empresas públicas}

Las primeras empresas públicas (con la excepción del correo que se creó en 1829) nacieron durante el impulso modernizador e intensamente reformista que caracterizó a los gobiernos batllistas de las tres primeras décadas del siglo $\mathrm{XX}^{3}$.

En 1911, quince años después de su fundación, el BROU fue estatizado definitivamente. En el mismo año, se creó el BSE, enfrentando la fuerte oposición de las compañías británicas y su embajada. Al año siguiente fue estatizado el BHU (Cuadro 1).

\section{Cuadro 1: Reseña de las empresas públicas financieras en Uruguay}

\begin{tabular}{|c|c|c|c|c|}
\hline $\begin{array}{l}\text { Empresas } \\
\text { Públicas }\end{array}$ & $\begin{array}{c}\text { Año de } \\
\text { fundación o } \\
\text { estatización }\end{array}$ & $\begin{array}{l}\text { Sector de } \\
\text { actividad }\end{array}$ & Régimen de competencia & $\begin{array}{l}\text { Forma } \\
\text { Jurídica }\end{array}$ \\
\hline $\begin{array}{c}\text { BHU (Banco } \\
\text { Hipotecario del } \\
\text { Uruguay) }\end{array}$ & $\begin{array}{l}1892 \text { mixta, } \\
\text { desde } 1912 \\
\text { estatal }\end{array}$ & $\begin{array}{c}\text { Préstamos } \\
\text { hipotecarios }\end{array}$ & $\begin{array}{c}\text { Desde } 1996 \text { en } \\
\text { competencia }\end{array}$ & $\begin{array}{c}\text { Ente } \\
\text { autónomo }\end{array}$ \\
\hline $\begin{array}{l}\text { BROU (Banco } \\
\text { de la República } \\
\text { Oriental del } \\
\text { Uruguay) }\end{array}$ & 1896 & Banca & $\begin{array}{c}\text { En general, en } \\
\text { competencia. Tuvo varios } \\
\text { ámbitos de actividad } \\
\text { monopólica, incluso de } \\
\text { emisión de panel moneda }\end{array}$ & $\begin{array}{c}\text { Ente } \\
\text { autónomo }\end{array}$ \\
\hline $\begin{array}{l}\text { BSE (Banco } \\
\text { de Seguros del } \\
\text { Estado) }\end{array}$ & 1911 & Seguros & $\begin{array}{l}\text { emision de papel moneda. } \\
\text { Actualmente en } \\
\text { competencia. Antes tuvo } \\
\text { monopolio en algunos } \\
\text { tipos de seguros. }\end{array}$ & $\begin{array}{c}\text { Ente } \\
\text { autónomo }\end{array}$ \\
\hline
\end{tabular}

\section{Fuente: Elaboración propia.}

3 El batllismo (por su fundador José Batlle y Ordońez, que ejerció la presidencia del Uruguay en I903-I907 y en I 9 I I-I9I 5) se caracterizó por su avanzada política social (legislación obrera, apoyo a la sindicalización, ley de divorcio, pensiones a la vejez, expansión de las jubilaciones, enseñanza media) y modernización y diversificación de la economía, impulso industrializador y gran expansión del Estado. 
También en 1912 se fundó UTE que tuvo el monopolio de la generación, transmisión y distribución de la energía eléctrica en todo el país (Cuadro 2). En las décadas siguientes UTE se expande al Interior estatizando y creando usinas, proceso que culmina en 1947 con la expropiación de la última usina particular.

\section{Cuadro 2: Reseña de las empresas públicas industriales o comerciales en Uruguay}

\begin{tabular}{|c|c|c|c|c|}
\hline Empresas Públicas & $\begin{array}{c}\text { Año de } \\
\text { fundación o } \\
\text { estatización }\end{array}$ & $\begin{array}{l}\text { Sector productivo } \\
\text { - Actividad }\end{array}$ & $\begin{array}{l}\text { Régimen de } \\
\text { competencia }\end{array}$ & Forma Jurídica \\
\hline $\begin{array}{l}\text { UTE (Administración } \\
\text { Nacional de Usinas } \\
\text { y Trasmisiones } \\
\text { Eléctricas) }\end{array}$ & 1912 & $\begin{array}{l}\text { Electricidad (y } \\
\text { teléfonos desde } \\
1931 \text { hasta 1974) }\end{array}$ & $\begin{array}{l}\text { Monopolio } \\
\text { (1997 cierta } \\
\text { liberalización } \\
\text { del sector) }\end{array}$ & Ente autónomo \\
\hline $\begin{array}{l}\text { ANP (Administración } \\
\text { Nacional de Puertos) }\end{array}$ & $\begin{array}{c}1916 \\
\text { Administración } \\
\text { del Puerto de } \\
\text { Montevideo } \\
\text { en monopolio. } \\
1933 \text { monopolio } \\
\text { sobre todos los } \\
\text { puertos del país }\end{array}$ & $\begin{array}{c}\text { Transporte fluvial } \\
\text { y marítimo }\end{array}$ & $\begin{array}{l}\text { En monopolio } \\
\text { y competencia, } \\
\text { dependiendo } \\
\text { del ámbito de } \\
\text { actividad de } \\
\text { que se trate }\end{array}$ & $\begin{array}{c}\text { Servicio } \\
\text { descentralizado }\end{array}$ \\
\hline $\begin{array}{c}\text { ANCAP } \\
\text { (Administración } \\
\text { Nacional de } \\
\text { Combustibles, alcohol } \\
\text { y Portland) }\end{array}$ & 1948 (desde & $\begin{array}{c}\text { Refinería y } \\
\text { distribución de } \\
\text { combustibles y } \\
\text { producción de } \\
\text { cemento, alcoholes } \\
\text { y bebidas }\end{array}$ & $\begin{array}{l}\text { Monopolio } \\
\text { de refinería de } \\
\text { combustibles } \\
\text { y competencia } \\
\text { en el resto }\end{array}$ & Ente autónomo \\
\hline $\begin{array}{c}\text { AFE (Administración } \\
\text { de los Ferrocarriles del } \\
\text { Estado) }\end{array}$ & $\begin{array}{l}1915 \text { existen } \\
\text { unas pocas líneas } \\
\text { de Ferrocarriles } \\
\text { del Estado) }\end{array}$ & $\begin{array}{l}\text { Transporte } \\
\text { ferroviario }\end{array}$ & En monopolio & Ente autónomo \\
\hline $\begin{array}{l}\text { OSE (Administración } \\
\text { de las Obras Sanitarias } \\
\text { del Estado) }\end{array}$ & 1952 & $\begin{array}{l}\text { Agua en todo el } \\
\text { país y saneamiento } \\
\text { en el interior }\end{array}$ & En monopolio & $\begin{array}{c}\text { Servicio } \\
\text { descentralizado }\end{array}$ \\
\hline $\begin{array}{c}\text { ANTEL } \\
\text { (Administración } \\
\text { Nacional de } \\
\text { Telecomunicaciones) }\end{array}$ & 1974 & Telefonía & $\begin{array}{l}\text { Hereda el } \\
\text { monopolio } \\
\text { de UTE en } \\
\text { telefonía } \\
\text { básica. En } \\
\text { competencia } \\
\text { en telefonía } \\
\text { celular }\end{array}$ & $\begin{array}{c}\text { Servicio } \\
\text { descentralizado }\end{array}$ \\
\hline $\begin{array}{c}\text { Administración } \\
\text { Nacional de Correos }\end{array}$ & $\begin{array}{l}1829 \text { dentro del } \\
\text { presupuesto, } \\
\text { desde } 1996 \\
\text { servicio } \\
\text { descentralizado }\end{array}$ & $\begin{array}{c}\text { Correspondencia y } \\
\text { logística }\end{array}$ & $\begin{array}{c}\text { Monopolio } \\
\text { desde } 1915, \\
\text { desde } 1996 \text { en } \\
\text { competencia }\end{array}$ & $\begin{array}{c}\text { Servicio } \\
\text { descentralizado }\end{array}$ \\
\hline $\begin{array}{c}\text { ANV (Agencia } \\
\text { Nacional de Vivienda) }\end{array}$ & 2008 & $\begin{array}{l}\text { Función: mejorar } \\
\text { el acceso a la } \\
\text { vivienda }\end{array}$ & & $\begin{array}{c}\text { Servicio } \\
\text { descentralizado }\end{array}$ \\
\hline
\end{tabular}

Fuente: Elaboración propia. 
El proceso de estatización de las comunicaciones culmina también durante el período batllista, con el establecimiento del monopolio estatal de los correos, telégrafos y teléfonos. Se establecía que se fijaría por decreto la fecha en que empezaría a hacerse efectivo el monopolio, mientras tanto podrían seguir operando las empresas privadas habilitadas o que se habilitasen en el futuro. Por lo tanto, el monopolio sólo era efectivo para el correo. La ley creaba la Administración General de Correos, Telégrafos y Teléfonos, dotada de personalidad jurídica. En 1931 se autorizó a UTE a hacerse cargo de la construcción y explotación de la nueva red telefónica nacional y a ejercer el monopolio de las comunicaciones por cable en todo el territorio nacional. La empresa UTE pasaba a denominarse Administración General de las Usinas Eléctricas y los Teléfonos del Estado. En 1933 se inauguró la red automática de teléfonos de Montevideo y cesaron las concesiones a las empresas privadas, que debían desmantelar sus redes aéreas. En los años siguientes la red se va a ir extendiendo al resto del país y cesando el servicio de las empresas privadas.

La compra por parte del Estado de los ferrocarriles británicos era una aspiración que no pudo concretarse en este período. En esa medida, el Estado comenzó la construcción o adquisición de ferrocarriles. En 1912 se estableció un fondo permanente para la construcción de ferrocarriles y en los años siguientes el Estado construyó o adquirió otras líneas de poca extensión. Ninguna de ellas entraba a Montevideo, y el control del sistema siguió estando en manos del Ferrocarril Central, la más importante de las dos compañías británicas que actuaban en el país. En 1930 las líneas explotadas por empresas privadas tenían una extensión de 2.457 kilómetros y las del Estado sólo 288 kilómetros.

Cuando se inauguró el puerto de Montevideo en 1909 se creó una comisión administradora que ejerció el monopolio del servicio hasta la creación en 1916 de la Administración Nacional del Puerto de Montevideo. En 1933 extendió sus atribuciones a todos los puertos de país, constituyéndose la Administración Nacional de Puertos (ANP). Antes de la construcción del puerto las operaciones de embarque y desembarque y traslado de mercaderías estaban en manos privados en régimen de competencia.

Entre 1928 y 1933 se produce una radicalización de las políticas reformistas, que fue denominado por la historiografía como "segundo impulso batllista”. Ante la crisis de 1929 se toman diversas medidas de protección a la industria, se establece el control de cambios, y en el plano que nos ocupa, se expande el Estado empresario con la creación del Frigorífico Nacional en 1928, el ya mencionado monopolio portuario de la ANP (1933) y el monopolio telefónico para UTE. 
Pero la obra más significativa fue la creación de ANCAP, el "ente industrial del Estado" como se le llamó. La ley fundacional le asignaba la misión de intervenir en tres ámbitos estratégicos. Respecto a los combustibles, establecía el monopolio estatal de la importación y refinación del petróleo crudo y, a partir de la producción del $50 \%$ de la nafta consumida en el país, tendría el monopolio de la importación y exportación de todo tipo de carburante. En cuanto a los alcoholes, establecía el monopolio sobre la importación, exportación y fabricación de alcohol y de las bebidas alcohólicas destiladas. Finalmente, se autorizaba la instalación de fábricas de portland para abastecer las necesidades de las obras públicas.

La empresa debió enfrentar desde su creación la oposición de empresarios nacionales que se veían afectados por el monopolio del alcohol y al trust internacional del petróleo que suministraba al país los subproductos y que eran apoyados por sus embajadas. ANCAP debía importar combustible refinado hasta que instalara su refinería y obtener el suministro de crudo del exterior a partir de ese momento. Ante la hostilidad de las petroleras se llegó a un acuerdo para el suministro de crudo con la empresa soviética Iuyamtorg, que aceptaba productos uruguayos como parte de pago. En los siguientes años ANCAP hizo efectivo el monopolio sobre el alcohol con la instalación de la primera destilería y comenzó la elaboración de varias bebidas alcohólicas. En 1937 se inauguró la refinería.

El golpe de Estado de 1933 protagonizado por el presidente en ejercicio Gabriel Terra, significó el fin del impulso estatista. Durante el período terrista que llega hasta 1938, se advierte que, sin que se produjera un cambio radical respecto al proceso estatista, este se debilita, lo que es congruente con las tendencias antiestatistas que predominaban en el régimen dictatorial. Esto se evidencia en las trabas puestas a la implementación del monopolio por parte de ANCAP y en la forma organizativa privada que adoptó CONAPROLE (Cooperativa Nacional de Productores de Leche), la otra importante empresa industrial creada por iniciativa estatal en el período.

\section{El auge del Estado empresario}

La etapa de culminación del intervencionismo estatal y del Estado empresario, coincide con el período de industrialización por sustitución de importaciones (ISI) en Uruguay, entre la Segunda Guerra Mundial y los inicios de la década del setenta. Con la particularidad que en este país el éxito de la industrialización referida tuvo corta duración y desde los últimos años cincuenta se entró en un largo estancamiento económico, desocupación y deterioro del Estado de bienestar construido en los años anteriores, y también de sus empresas públicas. 
El Estado empresario en los primeros años exitosos de la ISI tuvo una gran expansión debido al crecimiento de la cobertura y de las funciones de UTE y de ANCAP, así como al aumento del número de empresas principalmente por la estatización de las empresas británicas de servicios (la mayor parte de los ferrocarriles existentes, los tranvías de Montevideo y la compañía de Aguas Corrientes de Montevideo), el pasaje de la línea aérea PLUNA de empresa privada a empresa mixta en 1944 y a empresa estatal en 1952, y la fundación del SOYP, que en 1976 pasó a denominarse ILPE (Cuadros 2 y 3 ).

En 1947 UTE logra el monopolio eléctrico en todo el país. En el mismo año estableció una estructura de tarifas única nacional, con independencia de los costos de producción del servicio, lo que significó una importante rebaja para el Interior. El mayor destino de la electricidad fue el industrial y comercial, pero el uso residencial registró un fuerte crecimiento, en el marco de caída persistente y significativa de las tarifas reales. Otra característica fue la importancia de las inversiones, entre 1945 y 1960 se construyen las dos primeras represas hidroeléctricas del país y se amplió significativamente la principal central térmica del sistema mixto. Obras financiadas a través de los primeros préstamos internacionales que toma la empresa, principalmente con el BIRF.

La expansión de ANCAP fue muy importante en la posguerra luego de la situación crítica vivida durante la Segunda Guerra Mundial. Para 1940 comercializaba casi la mitad del combustible líquido consumido en el país y había impulsado la baja de las tarifas. Mediante sucesivas remodelaciones de la refinería de La Teja estuvo en condiciones desde 1947 de suministrar la totalidad de los combustibles líquidos requeridos por la demanda doméstica y de producir el fuel Oil necesario para el desarrollo industrial que estaba viviendo el país. Los cincuenta fueron años de gran expansión e inversiones, construyéndose una nueva refinería inaugurada en 1961. La ampliación de la capacidad de las destilerías de alcohol permitió hacia 1949 satisfacer la demanda interna de alcohol y bebidas. Paralelamente ANCAP promovía los cultivos de maíz y cebada para la producción de alcohol, así como el cultivo del azúcar de caña en las tierras adquiridas en El Espinillar, inaugurándose el ingenio en 1952. En estos años también se construyó una planta de portland, inaugurada en 1956.

En 1948, aprovechando que el Estado tenía congeladas en Inglaterra 17 millones de libras provenientes de los suministros efectuados durante la Segunda Guerra Mundial, se compraron a las empresas británicas los ferrocarriles por 7,15 millones de libras, fundándose AFE en 1952. Desde la segunda posguerra, los ferrocarriles dieron pérdidas en diversas regiones y países, presentaban atraso en las inversiones y enfrentaban resultados 
desfavorables respecto a la competencia del transporte automotor. Los resultados de AFE fueron permanentemente deficitarios, debido a la falta de inversiones de las empresas británicas previamente, las dificultades de competir con el transporte automotor y la no realización por parte de AFE de las grandes inversiones necesarias para reconvertir el servicio.

A partir de la compra de la compañía británica de aguas corrientes en 1950, se creó OSE en 1952, producto de la fusión de la ex-compañía privada de Aguas Corrientes de Montevideo y de la ex-Dirección de Saneamiento del Ministerio de Obras Públicas, existente desde 1907. Su Ley Orgánica estableció que: "La prestación del servicio y los cometidos del organismo deberán hacerse con una orientación fundamentalmente higiénica, anteponiéndose las razones de orden social a las de orden económico" (Art. 3). De acuerdo a estos objetivos, en este período los egresos de OSE superaron a sus ingresos, rigiendo además una tarifa social.

En los sesenta y comienzo de los setenta se producen las últimas creaciones de empresas públicas. Se estatizan varias empresas en crisis (tres frigoríficas y una textil) y el Estado adquiere en 1970 la británica Compañía del GAS que también estaba en aprietos (Cuadro 3). 


\section{Cuadro 3: Reseńa de las empresas públicas desaparecidas o privatizadas en Uruguay}

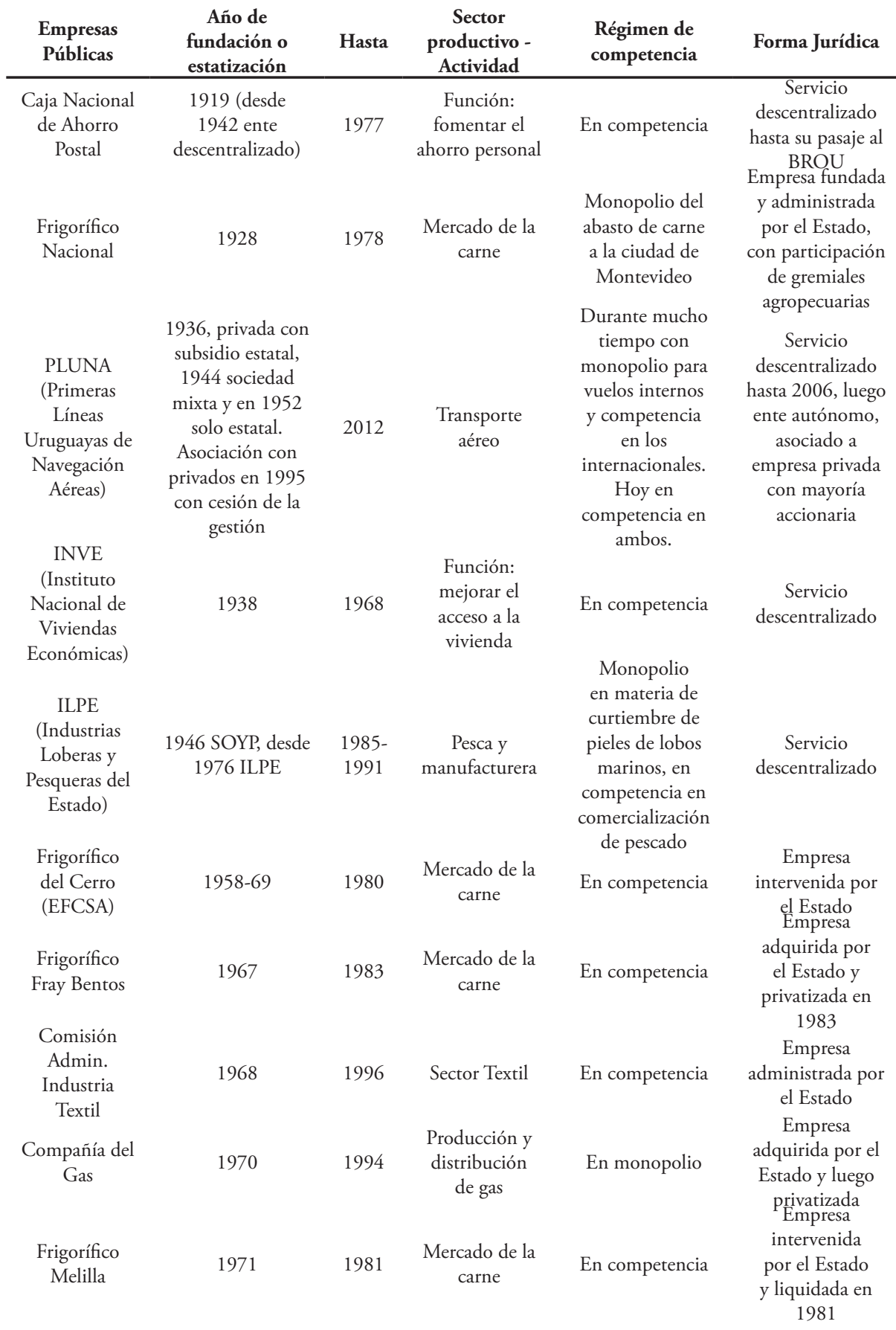

Fuente: Elaboración propia. 
En este período de detención de la expansión de las empresas el personal ocupado continuó creciendo, lo que puede vincularse con el estancamiento del desarrollo industrial y el consecuente aumento de la desocupación (Azar et al. 2009).

En esos años las finanzas de las empresas debieron enfrentar la devaluación de la moneda -que dificultaba el pago de las deudas en dólares contraídas durante las considerables inversiones realizadas en los cincuenta- y el recargo fijado a las importaciones, factores que llevaron a una importante alza de los costos. La resistencia a adecuar las tarifas a los costos (o las dificultades para hacerlo ante la velocidad del proceso inflacionario), causó a las empresas grandes pérdidas.

\section{El PREDOMINIO LIBERAL}

De igual forma que a nivel global, en Uruguay comenzará a plantearse la necesidad de acciones hacia una mayor eficiencia de las empresas públicas (preocupación manifestaba desde los sesenta) y la reducción de sus ámbitos de actuación. Este proceso se profundizará en los ochenta y especialmente en los noventa.

Durante la dictadura (1973-1985) y en el primer gobierno institucional (1985-1990), más que supresión de empresas públicas de relevancia primará, por la vía de los hechos, la liquidación de actividades consideradas no estratégicas. ANCAP vendió la bodega de Joanicó y el ingenio de El Espinillar, al tiempo que se cierran o vuelven a manos privadas los tres frigoríficos administrados por el Estado y el Frigorífico Nacional, comienza la liquidación del ILPE y de la Caja de Ahorro Postal. En 1987 se suprimió el servicio de pasajeros en AFE. En materia de empleo, algunas empresas sufrieron muy importantes caídas de su personal, en particular ANP y ANCAP.

En este período se establecieron las "tarifas realistas" (que cubren los costos más una cierta rentabilidad), aunque en los momentos de crisis se pasó a "tarifas políticas" para evitar intensificar la recesión. De la misma forma hubo esfuerzos que fracasaron para eliminar los subsidios del gobierno central, aunque estos se redujeron fuertemente hacia fines de los ochenta. Paralelamente se realizaron grandes inversiones en infraestructura aprovechando la abundancia de capitales a nivel mundial, lo que explica en parte las dificultades de las empresas a partir de la crisis y devaluación de 1982.

Se puede sostener que la dictadura no se planteó la privatización de las grandes empresas públicas, debido quizás a que dentro del gobierno 
militar, a diferencia de otros países latinoamericanos, la presencia de liberales a ultranza era más débil. En efecto, su política económica mostró contradicciones entre un discurso neoliberal y una práctica intervencionista.

A principios de los noventa, la propuesta privatizadora aparece con mayor fuerza. Pero, cuando se planteó la concesión a privados de servicios públicos, mediante la llamada popularmente "ley de privatizaciones" de 1991, hubo una respuesta negativa de un amplio sector de la ciudadanía (72\%) que frenó la iniciativa a través de un referéndum en 1992.

No obstante, desde fines de los ochenta habrá un proceso gradual de traslados de actividades hacia el sector privado desde el conjunto de las empresas públicas. Se cierra definitivamente el ILPE, se reprivatiza la Compañía del Gas y PLUNA tendrá mayoría de capital privado en su paquete accionario. Se reduce parte de las actividades de ANCAP, como los alcoholes y la sección de productos químicos. Se desmonopoliza la producción de alcoholes, la generación de energía eléctrica, los seguros, la telefonía celular y las funciones del correo. Otras vías de reducción del accionar de las empresas públicas fueron las concesiones de obras y servicios públicos y las asociaciones mixtas.

En las últimas décadas se advierte un fenómeno de importancia económica y política: la creación de numerosas sociedades anónimas pertenecientes a empresas públicas. Se trata de cerca de 30 empresas, en gran parte pertenecientes a ANCAP. En su mayoría habrían sido creadas porque no computan sus actividades para el cálculo del déficit fiscal, lo que las hace más libres en el manejo de sus inversiones, y de su personal, que puede operar bajo el derecho privado.

En paralelo, durante los noventa, se efectuó una fuerte y sostenida reducción de los funcionarios de todas las empresas públicas, hasta 2005 cuando el proceso se revierte marginalmente. Asimismo, se desarrolló toda una nueva reglamentación tendiente a priorizar un manejo rentable de las empresas bajo una concepción de cobrar según el coste marginal del bien o servicio, procurando a su vez procesos de mejora de gestión, al menos en algunas empresas públicas.

En 2003 vuelve a ponerse freno a los mayores avances del proceso con la eliminación por consulta popular de la ley que autorizaba la asociación de ANCAP con privados en la refinación de petróleo.

Desde los ańos noventa el servicio de agua y saneamiento en la zona balnearia de Canelones y Maldonado había sido concedido en gran parte a empresas privadas. En 2004 se sometió a plebiscito y se aprobó una 
reforma constitucional que revertió dicho proceso, declarándose que "el agua es un recurso natural esencial para la vida. El acceso al agua potable y el acceso al saneamiento, constituyen derechos humanos fundamentales", y que ambos servicios "serán prestados exclusiva y directamente por personas jurídicas estatales".

Finalmente, es necesario considerar los cambios que se pueden advertir en la orientación de las empresas públicas no financieras por parte de los gobiernos frenteamplistas desde 2005. La experiencia parece ser diferente en las distintas empresas.

Las tres empresas públicas más importantes (UTE, ANCAP y ANTEL), pusieron en marcha estrategias con lógica desmercantilizadora. En el sector de las telecomunicaciones, la estrategia de ANTEL es "conquistar y consolidar el control de las vías, terrestre y aérea, de la banda ancha. El objetivo es garantizar que este sistema no se construya y se gestione con lógica de mercado, sino con lógica de servicio público de expansión de derechos universales de acceso, con independencia del poder de compra, individual, empresarial o regional" (Narbondo 2012: 20). La política de UTE es fortalecer la matriz energética reforzando la integración e interconexión con la región, y promoviendo fuentes de generación eléctrica renovable. ANCAP además de intervenir en la producción de hidrocarburos, se ha empeñado en desarrollar la capacidad nacional de producir biocombustibles, reactivando la producción de caña de azúcar en el norte, con lo que, además de crear empleo en una zona carente de fuentes de trabajo, busca producir etanol.

Es de destacar, que tanto esta propuesta de ANCAP, como uno de los principales planes de inversión de OSE (saneamiento en Canelones) y otras actividades, se desarrollan bajo el mecanismo de SA de propiedad de las empresas públicas.

A su vez, en empresas tradicionalmente deficitarias como PLUNA y AFE, la política parece inclinarse hacia la mercantilización y el dominio del capital privado. En ese sentido, la segunda experiencia de privatización y gestión privada en PLUNA durante 2006-2012, significó la pérdida por parte del Estado del control de la orientación estratégica de la empresa. Cuando el socio mayoritario se retiró, la empresa fue cerrada de manera abrupta por el gobierno, para poder frenar las posibles demandas privadas contra la misma. Ante esta situación el gobierno estudia la venta y entrega de gestión de la compañía o las líneas aéreas de bandera al sector privado, o que la empresa sea administrada por los trabajadores. "En ese sentido cabe preguntarse si una política de competitividad sistémica en el transporte aéreo no requiere, como en el caso del trasporte ferroviario, subsidios 
públicos. En tal caso, si el Estado controla la propiedad y la gestión, por lo menos se garantiza que si hay dificultades financieras no es por vaciamiento o por excesivas ganancias del privado, que si es necesario el apoyo financiero estatal, éste no está subsidiando las ganancias privadas y finalmente que la gestión y el plan de negocios son conformes a los objetivos de competitividad sistémica que busca el Gobierno" (Narbondo 2012: 24). Del mismo signo parece ser la propuesta de reforma de AFE consistente en dividir la empresa estatal en dos. Una de derecho público, en la función no rentable del tendido y mantenimiento de las vías. La otra de derecho privado, que debe ser rentable y que no puede recibir subsidios del Estado, a cargo de administrar el servicio de trenes y de buscar asociaciones con inversores privados. Cabe suponer, al decir de Narbondo, que "si son éstos los que aportan el capital, los trenes correrán en las líneas rentables y no correrán en aquellas que no sean rentables" (2012: 24).

De lo expuesto hasta aquí, puede afirmarse que Uruguay no fue la excepción a la tendencia reformista desde los setenta, más allá de que no culminó con un proceso amplio de privatizaciones. Las empresas públicas uruguayas recorrieron un camino de reformas -tal cual lo describen Del Campo y Winkler (1992) para Argentina, Chile y México- similar, aunque más gradualista, al de otros países de América Latina que privatizaron la mayoría de sus empresas. Se reperfilaron los objetivos de las empresas dándole relevancia a la eficiencia económica y a la rentabilidad y luego de un proceso bastante largo y con retrocesos, se logró avanzar hacia tarifas más realistas y en la reducción de los subsidios. También se avanzó en la mejora de las estadísticas para el seguimiento y control de la gestión por parte del gobierno central. Se implantó la apertura comercial externa y se avanzó, si bien tímidamente hasta los noventa, en la desregulación de mercados vinculados a las empresas públicas no financieras. Existieron por otra parte durante la segunda mitad de los ochenta importantes programas de mejora de gestión y modernización. Finalmente, desde la dictadura de alguna forma se redefinió el tamaño del sector público y se eliminaron gran parte de aquellas actividades o empresas consideradas no estratégicas.

\section{DESEMPEÑO ECONÓMICO DE LAS PRINCIPALES EMPRESAS PÚBLICAS NO FINANCIERAS: 1912-2010}

\section{EVOLUCIÓN DE LAS PRINCIPALES VARIABLES ECONÓMICO-PRODUCTIVAS DE LAS EPNF5}

\section{Empleo y niveles de producción}

El Gráfico 1 permite ver parte de la dinámica productiva de las EPNF5 a lo largo del tiempo, mostrando la evolución tanto de la productividad 
laboral (IPL), como de sus componentes (producción, IVF, y empleo).

\section{Gráfico 1: Empleo e Índices de Volumen Físico y de Productividad Laboral $(1914-2010,2010=100)$}

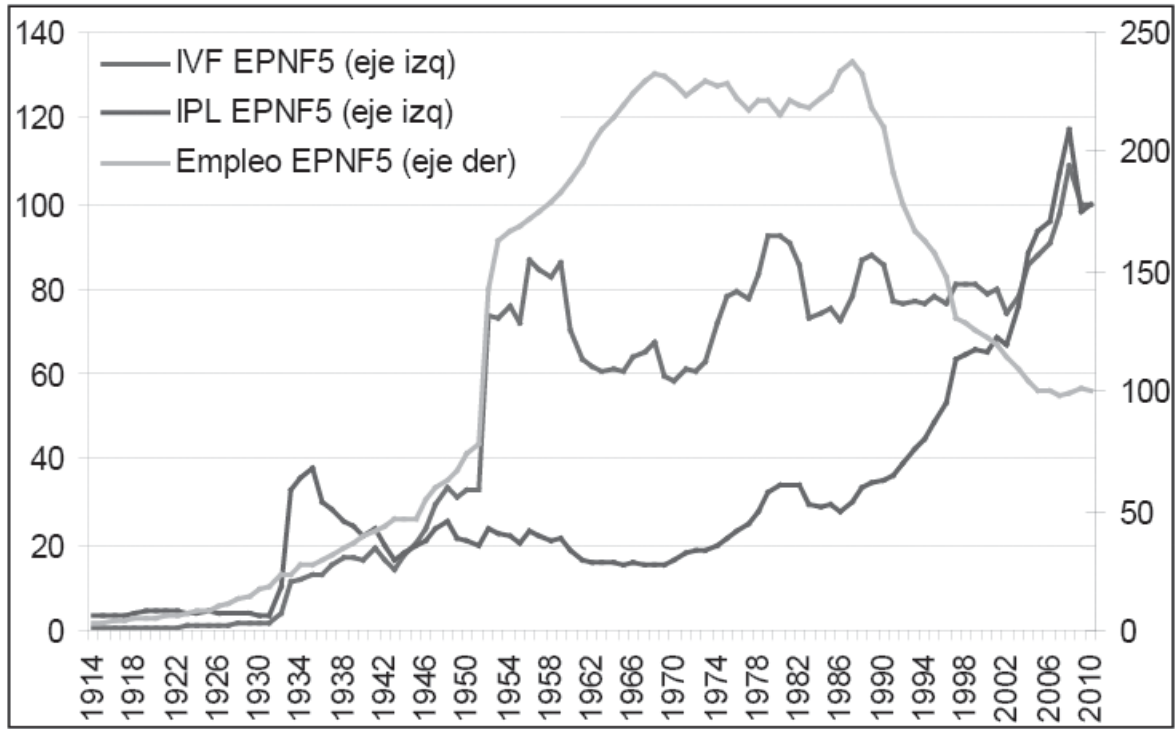

Fuente: Memorias de las empresas y otros organismos oficiales. Para empleo Azar et al. (2009).

El número de trabajadores de las empresas públicas ${ }^{4}$ creció ininterrumpidamente hasta 1973 (al igual que el total de funcionarios públicos), mientras las EPNF5 alcanzaron su máximo a fines de los sesenta. El peso en la PEA fue significativo, llegando las empresas públicas a representar un 6\% en los sesenta, $4 \%$ pertenecientes a las EPNF5. A partir de 1974, ya en el marco de la etapa liberal, dicha participación disminuye año a año, caída que se acelera en los noventa hasta situarse en 1,6\% de la PEA en 2010, y algo similar ocurre con las EPNF5 que caen a solo $1 \%$.

El fuerte incremento de los trabajadores de las empresas públicas a fines de los cuarenta e inicio de los cincuenta, es resultado de la etapa de apogeo del Estado empresario, cuando se fundaron nuevas empresas públicas no financieras, en particular AFE y OSE, que incorporaron los trabajadores de las empresas estatizadas. AFE nació con más de 11.000 empleados, casi $40 \%$ del total de los pertenecientes a las EPNF5 y casi 30\% de las empresas públicas en 1952.

4 Las empresas públicas incluyen aquí a las financieras y las no financieras, pero no el correo, ni los frigoríficos y la textil. 
Respecto al total de funcionarios públicos, el peso de los trabajadores de las EPNF5 aumenta hasta los cincuenta, llegando a $20 \%$ en dicha década, para luego decrecer hasta $8 \%$ en 2010 . Así, la reducción de funcionarios fue significativamente mayor en las EPNF5 que en el resto del Estado durante las últimas décadas de políticas liberales.

Por su parte, el IVF mantuvo una tendencia creciente, pero con importantes oscilaciones que se corresponden con la marcha de la economía, más allá de los saltos que produce la incorporación de empresas importantes como ANCAP, AFE y OSE en los años 1931, 1952 y 1953 respectivamente. Quizás las principales excepciones sean los noventa y los últimos ańos del período, cuando el IVF se estanca y cae respectivamente en el marco de un importante crecimiento de la economía, como resultado de la disminución de los volúmenes vendidos por ANCAP.

Durante las primeras décadas del siglo el IVF crece lentamente, porque se refiere sólo a la producción de UTE (donde si bien crece mucho la venta de electricidad, se trata aún de niveles muy bajos). El crecimiento importante que produce la creación de ANCAP, posiblemente se haya visto potenciado por efectos estadísticos ya que no solamente incorpora su producción, sino que además durante sus primeros ańos sus ingresos aumentaron considerablemente incrementando así su ponderación en el IVF agregado. De cualquier manera, es indiscutible el liderazgo de ANCAP sobre el comportamiento del IVF general tanto en este período como los siguientes, resultado de su alto peso en los ingresos de las EPNF5 $(\text { Gráfico 2) })^{5}$. Asimismo, la volatilidad de su IVF es mayor que en el resto de las empresas, que presentan -en tanto servicios públicos en red- una evolución estable al alza durante prácticamente todo el período.

Durante la Segunda Guerra Mundial se dio un descenso de los volúmenes producidos tanto en UTE como ANCAP, pero desde 1944 el IVF retomó su senda de crecimiento. El apogeo del estatismo marcó un incremento importante en el IVF de las EPNF5, producto tanto de la incorporación de AFE y OSE, como del aumento en las capacidades productivas de ANCAP y UTE (que comienza con la producción hidroeléctrica en 1946-1948). A pesar del reducido peso de AFE en los ingresos de las EPNF5, nunca superior a $11 \%$, su incorporación marcó un incremento significativo en el IVF agregado, que se diluye en los años siguientes a partir de la caída casi ininterrumpida de su producción.

5 En promedio alrededor de 60-65\% hasta los sesenta y $45 \%$ en los sesenta. A partir de la crisis del petróleo y el consiguiente aumento de precios de los combustibles, dicha participación crece hasta casi 75\%, luego caerá a 30\% en I999, para aumentar nuevamente hasta superar el 50\% en la actualidad, acompañando así básicamente la evolución del precio del crudo a nivel mundial en las últimas décadas. 


\section{Gráfico 2: Evolución del IVF de las EPNF5 (1912-2010, 2010 = 100)*}

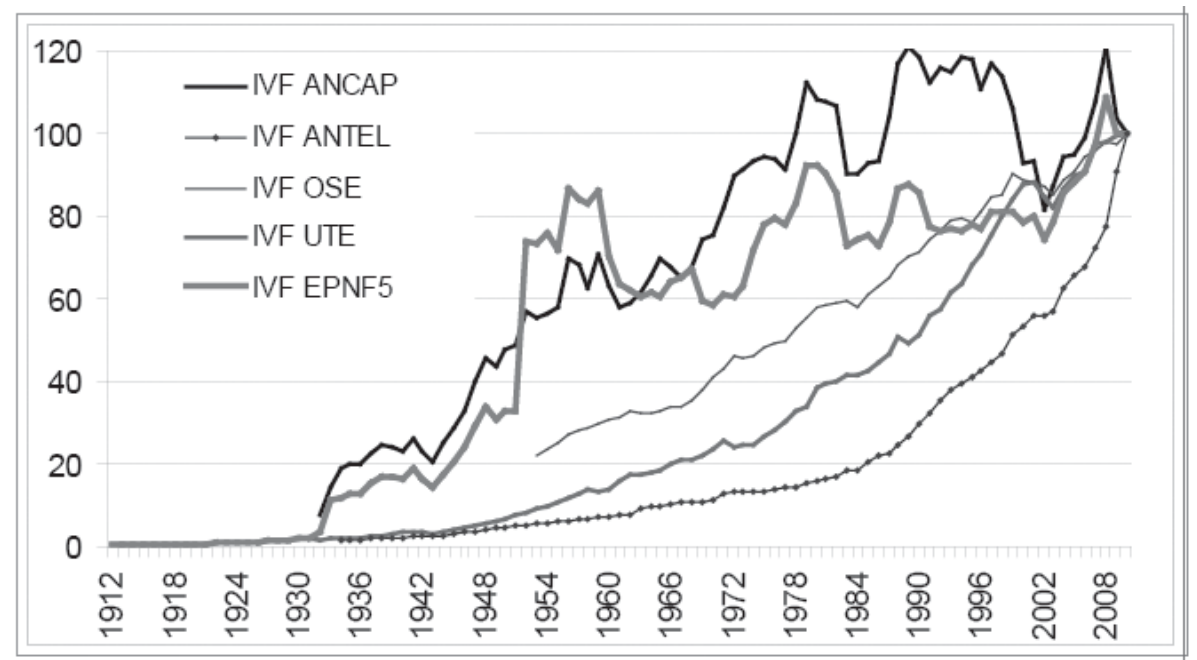

* Dada la trayectoria muy particular del IPL de AFE se excluye del gráfico para una mejor visualización.

\section{Fuente: Ídem Gráfico 1.}

El agotamiento del modelo ISI desde la segunda mitad de los cincuenta se refleja también en la evolución del IVF, siendo un período marcado por el estancamiento del índice, retomando el crecimiento a inicios de los setenta. Ahora bien, de excluirse AFE, el IVF de las EPNF5 presenta un marcado y continuo crecimiento ya desde 1964.

Ese crecimiento se profundizó en los setenta, en el marco de una nueva etapa de expansión económica, con fuertes inversiones por la abundancia mundial de capitales y el comienzo de un proceso de reformas que puede haber impactado en la gestión de las empresas. Luego, la crisis económica y la fuerte devaluación de inicio de los ochenta se hicieron sentir, sobre todo en ANCAP.

Debido al estancamiento de ANCAP en los noventa, el IVF agregado no crece, pese al muy fuerte incremento de UTE y ANTEL. El resto del período presenta oscilaciones, caracterizándose por comportamientos diferenciados por empresa. Durante la recesión y crisis de 2002, ANCAP, OSE y UTE vieron afectado su producción; luego de su recuperación nuevamente se registra un deterioro para ANCAP a partir de la crisis de 2008. ANTEL es la empresa que presenta mayor y más estable crecimiento. 


\section{Evolución de la productividad laboral}

$\mathrm{Al}$ igual que el IVF, las primeras décadas fueron de estabilidad en el IPL, hasta que en los treinta se produce un salto con la inclusión de ANCAP (Grafico 3). En sus primeros años de vida el IVF de ANCAP aumentó sin un incremento en el nivel de empleo, pero esto se invirtió en los ańos siguientes ${ }^{6}$.

Luego de un breve repunte desde los últimos años de la Segunda Guerra Mundial y de estabilidad durante los cincuenta, el IPL agregado -y siempre bajo la influencia decisiva de ANCAP- descendió en los sesenta. La tendencia se revertirá desde 1969.

Gráfico 3: Evolución del IPL de las EPNF5 (1914-2010, 2010 = 100)*

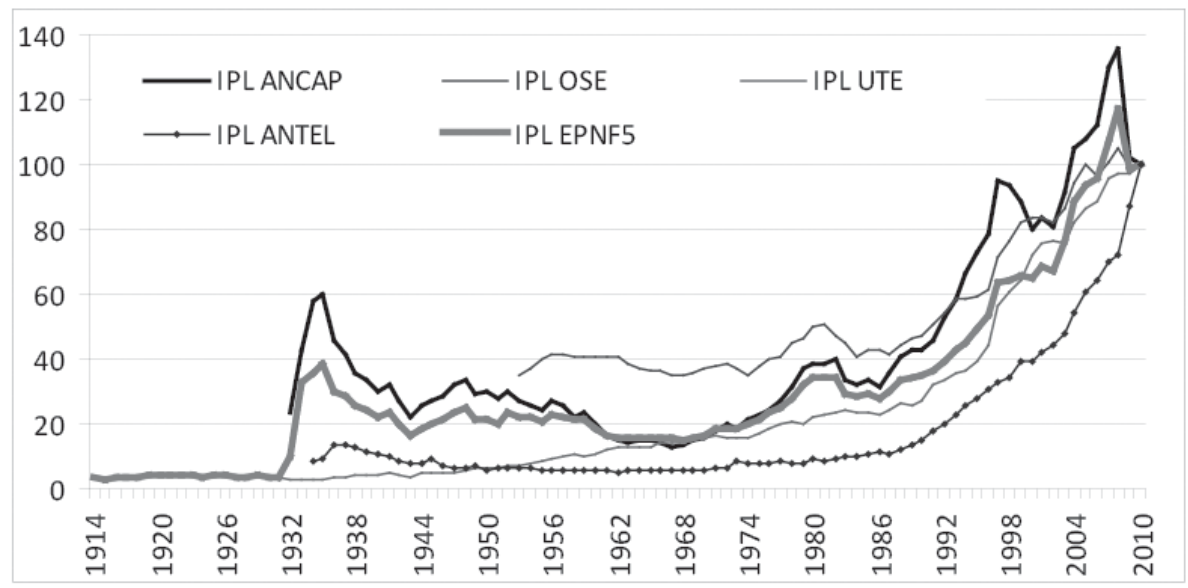

* Dada la trayectoria muy particular del IPL de AFE se excluye del gráfico para una mejor visualización.

Fuente: Ídem Gráfico 1.

A continuación, se observa lo sucedido con las variables que componen el IPL, de modo de visualizar cuál ha liderado su comportamiento en los diferentes subperíodos. Dado que no es posible desagregar exactamente el aporte de cada una, el Cuadro 4 brinda solo una aproximación al respecto para el período previo a los setenta.

6 Es que durante los treinta ANCAP pasó de la esfera de la sola comercialización al terreno industrial: elaboración de Grappa (I932), destilación de Alcohol (I934) y refinación de petróleo (I937). 


\section{Cuadro 4: Variación del IPL y sus componentes (1914-1972)}

\begin{tabular}{cccccc}
$\begin{array}{c}\text { Período } \\
\text { variación }\end{array}$ & Empleo & $\begin{array}{c}\text { Empleo } \\
\text { ponderado) }\end{array}$ & $\begin{array}{c}\text { IVF } \\
\text { general }\end{array}$ & $\begin{array}{c}\text { IPL } \\
\text { general }\end{array}$ & Conductor \\
\hline $1914-1930$ & $455 \%$ & $455 \%$ & $447 \%$ & $9 \%$ & $\begin{array}{c}\text { Ambas variables crecen de } \\
\text { forma significativa y casi } \\
\text { se compensan }\end{array}$ \\
$1931-1945$ & $172 \%$ & $79 \%$ & $985 \%$ & $442 \%$ & $\begin{array}{c}\text { Lidera aumento de IVF } \\
\text { Ambas variables crecen de } \\
\text { forma significativa y casi }\end{array}$ \\
$1946-1959$ & $292 \%$ & $77 \%$ & $256 \%$ & $8 \%$ & $\begin{array}{c}\text { se compensan } \\
\text { Ambas variables se }\end{array}$ \\
$1959-1972$ & $24 \%$ & $50 \%$ & $-30 \%$ & $-13 \%$ & \\
mueven en contra de IPL
\end{tabular}

Fuente: Ídem Gráfico 1.

La etapa de desarrollo del estatismo estuvo marcada en las empresas públicas no financieras consideradas por lo sucedido en UTE y ANCAP. El estancamiento en la productividad de UTE hasta 1930, quizás pueda explicarse por el hecho de que si bien su producción crece fuertemente, es un período de adquisición de Usinas del Interior, lo que seguramente haya impactado más en el aumento del empleo que en la producción, dado que el Interior consumía menos de 10\% del consumo montevideano. Por su parte, el gran aumento del IPL entre 1931 y 1945 es resultado básicamente de un salto de nivel, a causa del ingreso de ANCAP, que inicia sus actividades con un mayor valor de IPL que el que tenía la electricidad $\mathrm{y}$ con un alto nivel de ingresos.

Durante el crecimiento económico de los años de postguerra en el marco de la ISI, el importante crecimiento de la producción fue prácticamente compensado por el aumento del empleo a nivel agregado para las EPNF5. Ello como resultado de que: 1) ANCAP pese a registrar el mayor aumento de IVF, no logra aumentos de productividad porque también crecen en forma muy importante sus funcionarios $(\text { Gráfico } 4)^{7} ; 2$ ) el aumento de productividad en UTE (cuyas ventas crecen 10\% acumulativo anual), es casi compensado por la caída en la telefonía dado el fuerte aumento de su empleo; y 3) OSE si bien aumenta su productividad en sus primeros ańos, lo hace muy moderadamente.

$7 \quad$ Desde fines de los cuarenta se desarrolla fuertemente la producción de alcoholes y en la segunda mitad de los cincuenta la de portland. Además, en I957 se le asigna un nuevo objetivo, la producción de insumos químicos. 


\section{Gráfico 4: Evolución de los funcionarios de las EPNF5 (1912-2010)}

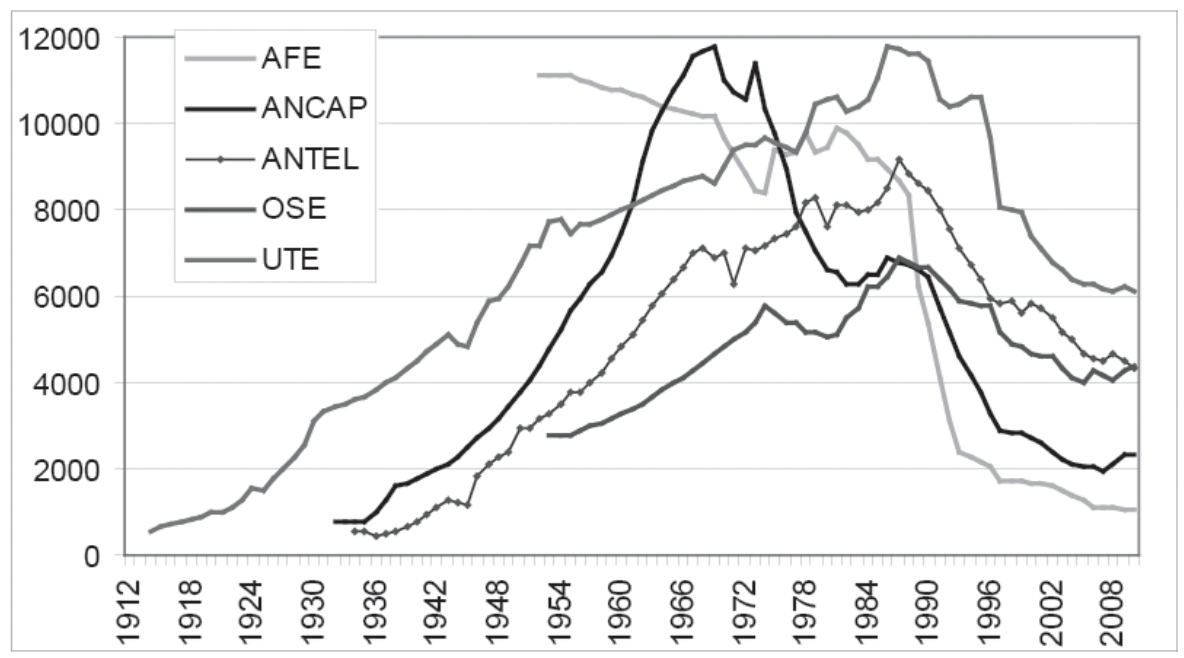

Fuente: Memorias y otras publicaciones de las empresas y Azar et al. (2009).

Ya en los sesenta, la caída del IPL responde fundamentalmente a la evolución de ANCAP, que profundizará en esa década la caída de su productividad observada desde fines de los cuarenta. El crecimiento de la productividad en UTE no logra compensar dicha caída, mientras que OSE y ANTEL muestran estabilidad en su IPL.

Por su parte, AFE, que mantuvo su productividad estable desde su creación, la disminuye desde los últimos años sesenta -pese a la continua caída del empleo- hasta fines de los ochenta, cuando cierra el transporte de pasajeros (1988) y acelera la reducción de su plantilla; no obstante, desde los setenta su peso es marginal.

Los setenta y los ochenta, en el marco de la etapa liberal, son años marcados por un importante crecimiento de la productividad de todas las empresas (salvo AFE), a partir del crecimiento del IVF general (Cuadro 5) y también de la fuerte reducción de funcionarios en ANCAP (alrededor de $40 \%$ en las dos décadas) ${ }^{8}$. Dicha caída junto a un importante aumento de sus ventas (salvo en los ańos posteriores a la crisis de 1982) permitió que ANCAP más que duplicara su productividad y, dado su muy alto peso en el indicador, que el IPL agregado también se duplique.

8 En i969 se aprobó luego de una consultoría al respecto, una nueva estructura orgánica que reagrupaba funciones.Se estimuló el pase a jubilación y se implantó el prejubilatorio para los funcionarios en edad de jubilarse. En 1975 se pasó de seis horas diarias a un horario de ocho horas. 
Por su parte, en ANTEL, OSE y UTE, el IPL la productividad crece incluso con aumento del empleo.

\section{Cuadro 5: Variación del IPL y sus componentes (1973-2010)}

\begin{tabular}{cccccc}
$\begin{array}{c}\text { Período } \\
\text { variación }\end{array}$ & Empleo & $\begin{array}{c}\text { Empleo } \\
\text { (ponderado) }\end{array}$ & $\begin{array}{c}\text { IVF } \\
\text { general }\end{array}$ & $\begin{array}{c}\text { IPL } \\
\text { general }\end{array}$ & "Conductor" \\
\hline $1973-1989$ & $-4 \%$ & $-14 \%$ & $45 \%$ & $\mathbf{8 6 \%}$ & Lidera aumento de IVF \\
$1990-1999$ & $-42 \%$ & $-34 \%$ & $-8 \%$ & $\mathbf{8 9} \%$ & Lidera descenso de empleo \\
$2000-2005$ & $-20 \%$ & $-31 \%$ & $8 \%$ & $\mathbf{4 3 \%}$ & Lidera descenso de empleo \\
$2006-2010$ & $-1 \%$ & $7 \%$ & $14 \%$ & $\mathbf{7 \%}$ & $\begin{array}{c}\text { Lidera moderadamente } \\
\text { aumento de IVF }\end{array}$
\end{tabular}

Fuente: Ídem Gráfico 1.

En los noventa la caída del empleo es muy significativa en todas las empresas públicas no financieras (Gráfico 4). Nuevamente, AFE y ANCAP lo reducen muy fuertemente (aproximadamente $75 \%$ y $55 \%$ en la década) y ahora también cae en ANTEL, OSE y UTE (en torno a 30\% en los tres casos), con lo cual la caída del empleo del conjunto de las EPNF5 es superior a $40 \%$. Ello se vincula no sólo con intentos de mejoras de gestión sino también con las mencionadas supresiones de actividades y tercerizaciones y concesiones en esos años.

La caída del IVF agregado oculta que, más allá de que ANCAP presenta niveles de venta estancados primero y en caída hacia el final del período -ya en un marco de recesión económica-, el resto de las empresas registran un significativo crecimiento en su IVF (92\% ANTEL, 71\% UTE y 29\% OSE).

El empleo sigue bajando durante el primer lustro del siglo XXI, si bien de forma algo más moderada, dejar de caer en las distintas empresas entre 2005 y 2008 (salvo en AFE), manteniéndose en el agregado.

No obstante, ya superada la crisis de 2002, el crecimiento del IVF en las distintas empresas es más que significativo, en particular en ANCAP y ANTEL, si bien a excepción de esta última la crisis de 2008 generó una merma o incluso una retracción del índice (fundamentalmente en el caso de ANCAP, cuyo IPL se reduce $23 \%$ entre 2007 y 2010). De esta forma, el IVF vuelve en el último subperíodo a explicar el moderado incremente del IPL. 


\section{Peso en el PIB del VAB de las EPNF5}

Por último, se observa otra forma complementaria de aproximación al desempeño de las EPNF5, que permite visualizar su significación en la generación de valor agregado de la economía. No obstante, representa sólo una primera aproximación a la contribución de las empresas públicas no financieras al PIB, siendo parte de la agenda realizar una estimación mejorada del $\mathrm{VAB}$ en términos constantes de las empresas públicas no financieras (Bertino et al. 2012b).

La importancia de las EPNF5 en relación al PIB se ha incrementado a lo largo de toda su existencia (Gráfico 5), siendo los años de mayor crecimiento entre mediados de los cuarenta y mediados de los cincuenta y durante los noventa. Durante el último cuarto de siglo los años de mayor expansión respecto al PIB son resultado de crisis de la economía, en tanto que en las fases de recuperación las empresas públicas no financieras pierden peso. Así ocurrió en la crisis de 1982 y durante la recesión y crisis entre 1998 y 2002.

El primer período de mayor crecimiento se caracterizó por la fundación de nuevas empresas públicas no financieras (AFE y OSE) y por la expansión de las empresas ya existentes. En cuanto a los noventa, dicho incremento puede que sea una combinación entre la expansión de la demanda de servicios públicos", la caída del costo laboral, tarifas vinculadas a costo marginal (e incluso con un posible componente recaudador en su fijación) y la implementación de fuertes inversiones y reformas de gestión.

9 Téngase presente que desde los setenta las empresas que contribuyen con una mayor participación en el VAB son: UTE, ANTEL y ANCAP, en ese orden aproximadamente. 


\section{Gráfico 5: Evolución del VAB de las empresas públicas no financieras}

(1912-2010)

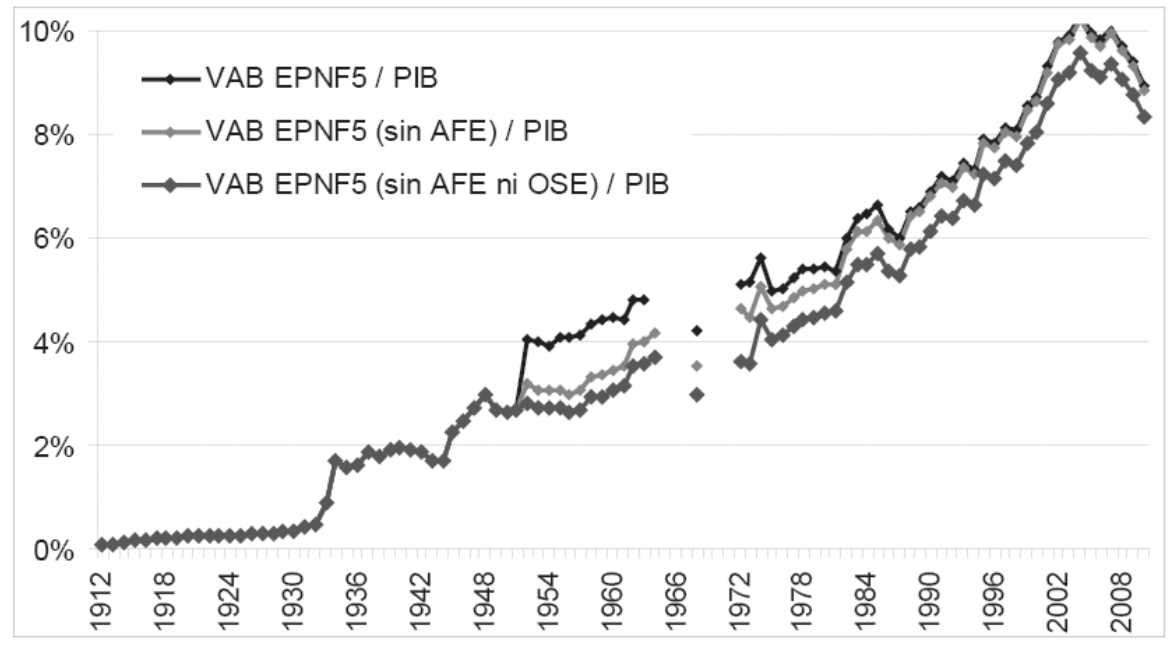

Fuente: Solari y Franco (1983), SCN 1965, Bertino y Tajam (1999), BCU e IVF de las EPNF5 elaborado.

Este indicador es importante porque las EPNF5 son intensivas en capital, por lo que si se estudian los activos fijos se las estará sobrevaluando y si se analizan las ventas o el empleo se las estará subvaluando. En este último sentido, hasta fines de los sesenta el peso en el PIB de las EPNF5 era solo levemente superior al peso de su empleo en la PEA, luego la diferencia no para de crecer. Mientras en los cincuenta y sesenta para generar 4-5\% del PIB las EPNF5 utilizaban 3-4\% de la PEA, en la última década utilizan solo poco más de $1 \%$ de la PEA para contribuir al PIB entre $8 \%$ y $10 \%$.

\section{EVOLUCIÓN ECONÓMICO-FINANCIERA DE LAS EPNF5}

Tanto los resultados (antes de trasferencias) de las EPNF5 como sus transferencias al gobierno central fueron positivos al menos hasta mediados del siglo XX y luego marcadamente desde los noventa (Gráficos 6a y 6b). No fue así durante el resto del período. Los resultados de las empresas existentes tendieron a empeorar ya desde los cincuenta, al tiempo que la inclusión de AFE y OSE acentuó la necesidad de crecientes subsidios directos.

Hasta fines de los años veinte las contribuciones de las EPNF5 representaron $1 \%$ de los ingresos del gobierno central y hasta mediados de los cuarenta entre $2 \%$ y $3 \%{ }^{10}$. Desde entonces se transformaron en un

Io De sumarse los bancos públicos (que aportaron casi el $65 \%$ del total de contribuciones 
costo para el gobierno central, sobre todo a raíz de los crecientes déficit de $\mathrm{AFE}^{11}$. En 1963 los subsidios directos eran algo más de 10\% de los ingresos del gobierno central (y más si se incluyen el resto de las empresas públicas no financieras existentes en ese momento, en general deficitarias). En los noventa y durante los dos mil, las transferencias vuelven a ser positivas y significativas para el erario público.

Ahora bien, la incidencia de AFE en los resultados y sobre todo en las transferencias netas con el gobierno central de las EPNF5, hace que se consideren dos escenarios: con y sin AFE. En el primer caso, las trasferencias netas se vuelven negativas luego de la incorporación de AFE en 1948, y permanecieron así hasta que el progresivo desmantelamiento de esta empresa desde fines de los ochenta le restó incidencia. En el segundo caso, aunque no se cuenta con datos para los complejos años sesenta, en líneas generales puede decirse que las empresas públicas no financieras consideradas no fueron en ningún momento un costo significativo para el fisco en términos de subsidios directos ${ }^{12}$. Ello no desconoce que fueron años donde existieron otros tipos de subsidios a las empresas públicas no financieras, "ocultos" o de difícil visualización, o bien "involuntarios", al decir de Boneo (1973), como exoneraciones tributarias o emisión de deuda pública para cubrir déficit o para realización de inversiones.

de las empresas públicas hasta mediados de los cuarenta), en torno a $5 \%$ de los ingresos del gobierno central y medio punto porcentual del PIB.

I I Los subsidios a AFE en sus primeros ańos rondaban el 20-25\% de los costos de operación y renovación del servicio, mientras que hacia finales de los cincuenta superaban el 50\%, siendo incluso mayor en algunos ańos, como en I963 (83\%) o en I $969(75 \%)$.

I 2 Incluso de sumarse los aportes de los bancos estatales, las transferencias netas se vuelven negativas solo en los sesenta y en años puntuales como I973-74 a causa de la crisis del petróleo. 


\section{Gráfico 6a y 6b: Resultados y Transferencias netas en términos del PIB (1912-2010)*}
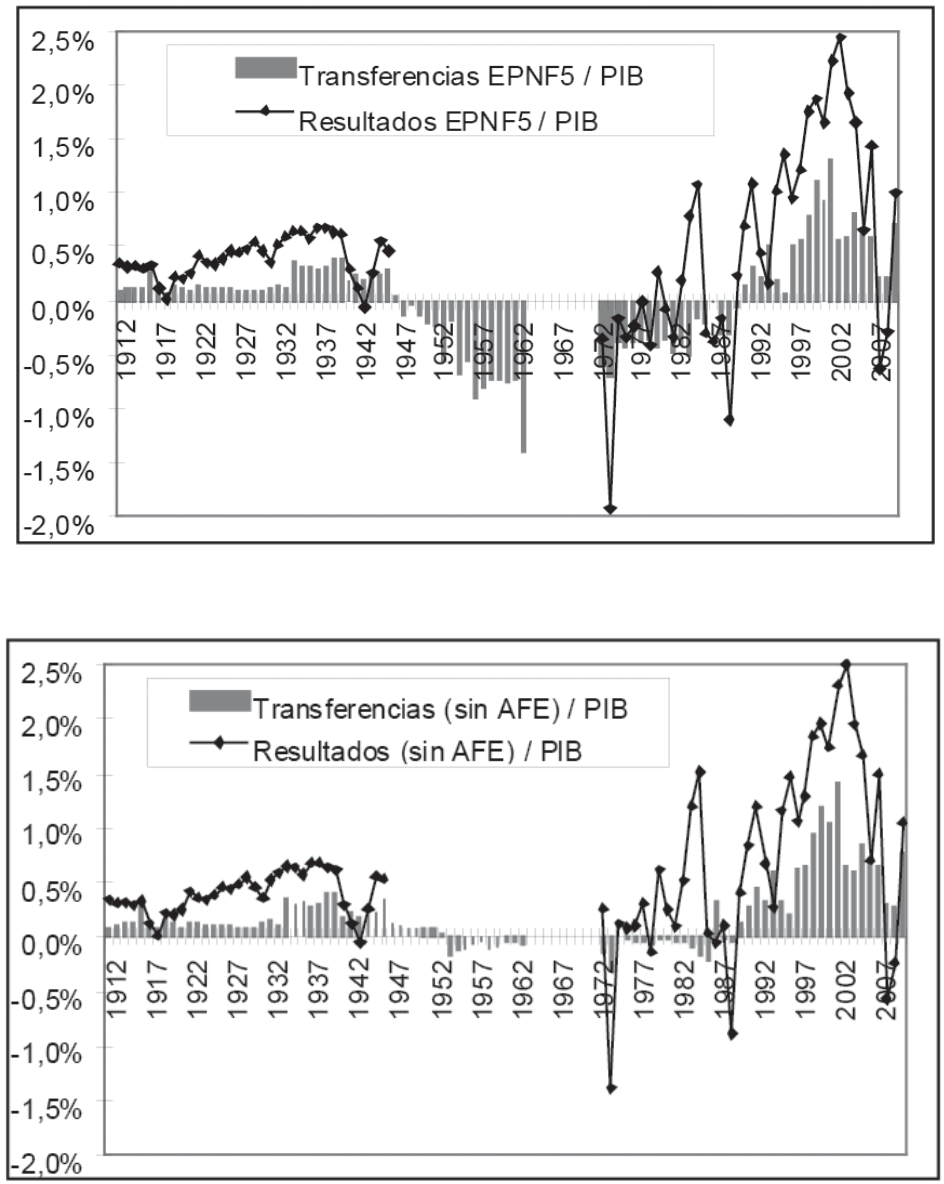

* Los resultados hasta I946 son de balances contables de las empresas (criterio de lo devengado). Desde I973 son de sus Ejecuciones Financieras (criterio caja, incluye costo total de las inversiones realizadas).

Fuente: Rodríguez López (1928), Acevedo (1936), Dondo (1942), anuarios estadisticos, leyes y decretos, OPP y memorias de las empresas.

Los resultados fueron en general negativos hasta fines de los ochenta, pero de excluirse AFE vuelven a ser positivos ya en los setenta ${ }^{13}$.

I 3 No obstante, debe señalarse que desde I 973 no se cuenta con las utilidades (resultados económicos) sino con resultados financieros, que si bien son en general similares, las diferencias se vuelven significativas en los ochenta, cuando estos se tornan muy negativos. Esto dado que los primeros no registran, como si lo hacen las utilidades -resultantes de los estados contables-, las obligaciones de servicios de deuda externa porque en general las empresas no pagaron dicho servicio en esos años, realizándolo de hecho el Estado. 


\section{Utilidades y contribuciones durante el nacimiento y consolidación de las empresas públicas no financieras}

Hasta mediados de los cuarenta tanto UTE como ANCAP tuvieron utilidades positivas, a excepción de UTE en 1942-43 (por problemas de abastecimiento y aumento del precio del petróleo por la Segunda Guerra Mundial). A su vez, fue un período donde UTE aportó al fisco (salvo en los ańos de la Segunda Guerra Mundial), aproximadamente entre 20\% y $40 \%$ de sus utilidades (en torno a $0,1 \%$ del PIB) ${ }^{14}$, mientras que ANCAP lo hizo en cerca del doble (Gráficos 7 a y $7 \mathrm{~b}$ ), insumiendo la mayor parte de sus utilidades.

\section{Gráfico 7a y 7 b: Utilidades y Transferencias netas de las EPNF5 en términos del PIB (1912-1945)}

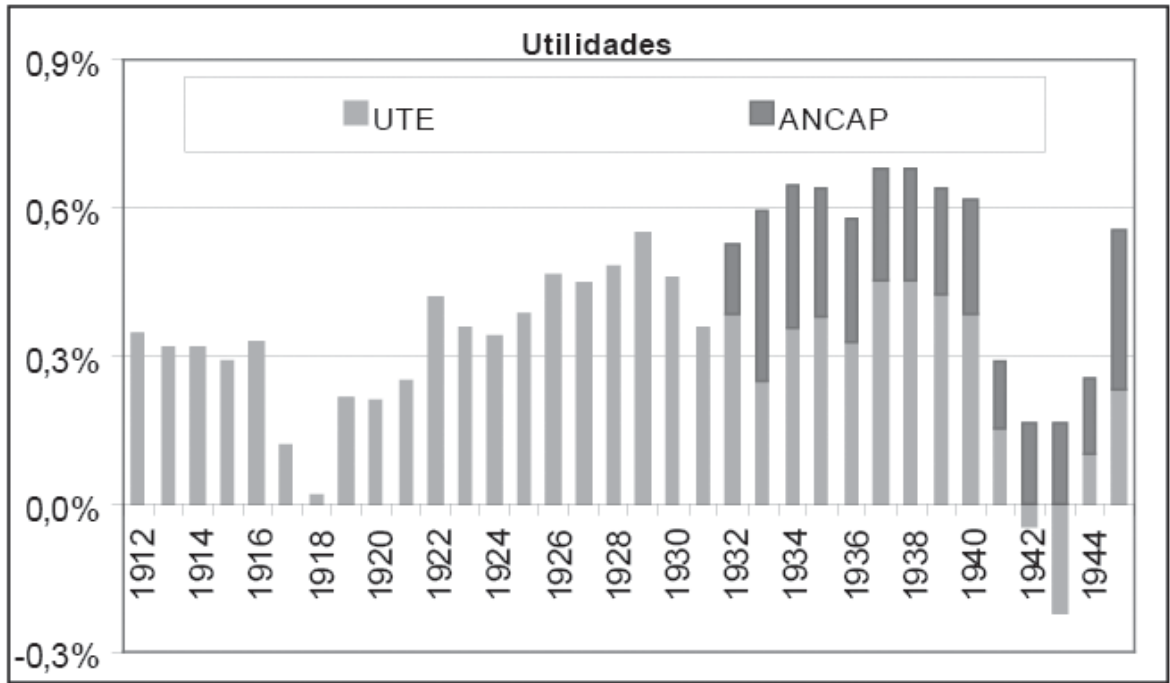

I4 Respecto a la distribución entre el sector electricidad y el de teléfonos de UTE, se cuenta con escasa información, pero puede afirmarse que el primero fue el que predominó marcadamente hasta I974. 


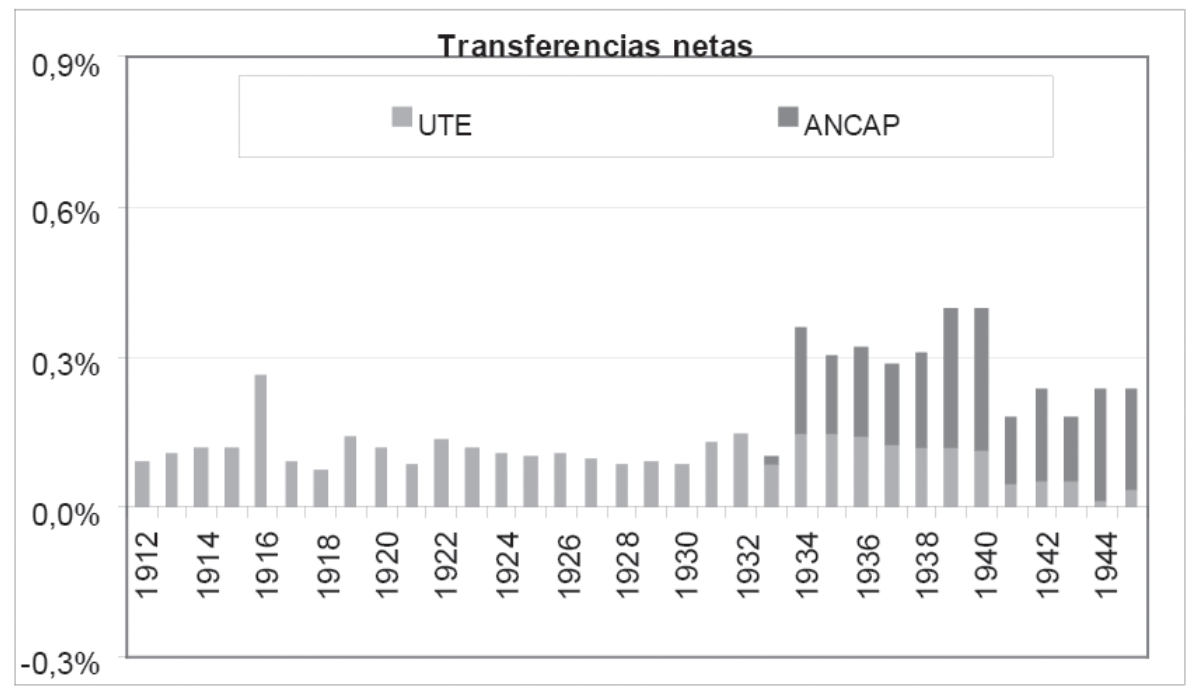

Fuente: Rodríguez López (1928), Acevedo (1936), Dondo (1942), anuarios estadísticos, leyes y decretos y memorias de las empresas.

Las propias leyes de creación de las primeras empresas públicas determinaron la asignación de las utilidades que produjeran. La filosofía de la empresa pública batllista sostenía que las utilidades debían quedar en las empresas. En el caso de UTE, por ejemplo, su ley de creación de 1912 estableció que se formara un fondo de reserva con el 10\% de sus utilidades y que con el resto se bajaran tarifas y se ampliaran las instalaciones.

No obstante, la propuesta de no utilizar los beneficios de las empresas públicas con fines fiscales, fue rápidamente matizada frente a los apremios fiscales que impuso la PGM. Así, por ejemplo UTE (junto al BROU) fue convocada a contribuir en dicha situación, aportando incluso por encima de sus utilidades entre 1916 y 1919. En 1931 y 1932, debido al impacto de la crisis de 1929, se deciden contribuciones extraordinarias de las empresas públicas. En 1934, bajo la dictadura de Terra, aumentaron en dos ocasiones los aportes, llegando a $80 \%$ sobre utilidades, lo cual triplicó lo aportado por las empresas públicas en 1935 respecto a 1931. Estas nuevas contribuciones, si bien se planteaban como transitorias, quedaron en aplicación hasta el final del gobierno de Terra (1938).

Nuevamente se establecieron contribuciones extraordinarias de varias empresas públicas frente a los apremios fiscales durante la Segunda Guerra Mundial, a partir de leyes de 1942 y 1944 y su renovación hasta 1946. Varias empresas públicas aportaron en igual monto o por encima de sus utilidades durante esos ańos, mientras que UTE fue eximida de gran parte 
de los suyos dado los fuertes impactos de la guerra en la empresa.

\section{El deterioro de los resultados durante el auge del Estado empresario}

Este subperíodo, para el cual no se cuenta con series de resultados de las empresas públicas no financieras, se caracterizó por la expansión del dominio empresarial estatal hacia empresas que eran a esa altura naturalmente deficitarias. En particular, AFE y OSE desmejoraron la performance financiera de las empresas públicas no financieras en su conjunto. AFE tuvo resultados negativos durante toda su existencia y OSE mayoritariamente hasta fines de los ochenta.

A ello se suman los déficits financieros desde inicio de los cincuenta (incluso presentando utilidades positivas en muchos casos) de UTE, ANP y otras empresas públicas no financieras menores. Para cubrirlos el gobierno central emitió deudas públicas. Para UTE ya en 1950 una colocación de deuda pública procuró licuar sus déficits financieros acumulados durante la segunda mitad de los cuarenta, resultado fundamentalmente de bajas tarifas y grandes inversiones. En ese marco, sus aportes al fisco no superarán el 20\% entre 1946 a 1958.

En cuanto a ANCAP, sus utilidades (únicos resultados disponibles) fueron negativas en 1965, 1967 y 1972, por fuertes aumentos del tipo de cambio en los dos primeros casos y por suba del precio del crudo en el tercero, dado el acuerdo de Teherán de 1971.

Las contribuciones brutas de las empresas públicas no financieras pierden peso, cayendo progresivamente en relación al PIB y a los ingresos públicos, en un marco donde se priorizan objetivos para la gestión de las empresas públicas de carácter no fiscalista, como generación de empleo en contextos recesivos, tarifas bajas para mejorar el acceso a servicios básicos o insumos de producción claves y contener la inflación.

En suma, en este período las principales empresas públicas no financieras continúan aportando positivamente, pero no logran revertir el déficit generado por AFE y OSE.

\section{El desempeńo financiero desde los setenta}

En los setenta se inician cambios en la concepción de las empresas públicas en varios frentes. Lo que más interesa aquí es que en materia de rentabilidad, primero para UTE en 1970 y luego para todas las empresas públicas no financieras en 1974 , se procura por ley una rentabilidad de $8 \%$ sobre capital invertido bajo una política de realismo tarifario. En cuanto a las contribuciones, por decreto-ley de 1976, será el Ejecutivo el que 
determine el destino de las utilidades de las empresas públicas. A su vez, en 1991 se establece que sus resultados finales (luego de transferencias) deben computarse en el cálculo del resultado fiscal del sector público.

De todos modos, el realismo tarifario se llevó muy marginalmente a la práctica (Bertino et al. 2012c). ANCAP y UTE no habrían alcanzado el $8 \%$ de rentabilidad, y las principales empresas deficitarias (AFE y OSE) si bien redujeron fuertemente sus déficit no llegaron a tener resultados positivos. Finalmente, en el caso de ANTEL, sus resultados serían negativos durante toda la década del setenta. Esto implicó que en las décadas del setenta y ochenta el costo fiscal de las empresas públicas no financieras (básicamente subsidios a AFE y en menor medida a OSE, mientras que las grandes empresas públicas no financieras no realizaron prácticamente aportes hasta los noventa) acompañó en líneas generales la evolución del déficit del gobierno central.

La evolución durante los noventa y comienzos del siglo XXI fue muy distinta. Las transferencias a AFE disminuyen por la reducción misma de su actividad y la ANP desde los setenta y OSE desde los noventa dejan de recibir transferencias, pasando en el primer caso incluso a ser contribuyente durante los últimos ańos. Ello contribuyó a que, en un contexto de muy positivos resultados financieros de las grandes empresas públicas no financieras (Gráficos 8a y 8b), las transferencias netas al gobierno central implicaron una reducción no despreciable del déficit fiscal del sector público ${ }^{15}$, mientras que en el país se debatía públicamente respecto a si sus tarifas eran utilizadas justamente con fines recaudadores.

Los mayores aportes fueron de ANTEL, que junto a UTE monopolizan las contribuciones en las últimas décadas (Gráficos $8 \mathrm{a}$ y 8b).

I5 Algo más de medio punto del PIB durante las dos últimas décadas, y sumando los resultados luego de transferencias el aporte neto total de las EPNF5 fue levemente superior a un punto del PIB. 


\section{Gráfico 8a y 8b: Resultados financieros y Transferencias de las EPNF5 (1973-2010, a precios constantes de 2010)}
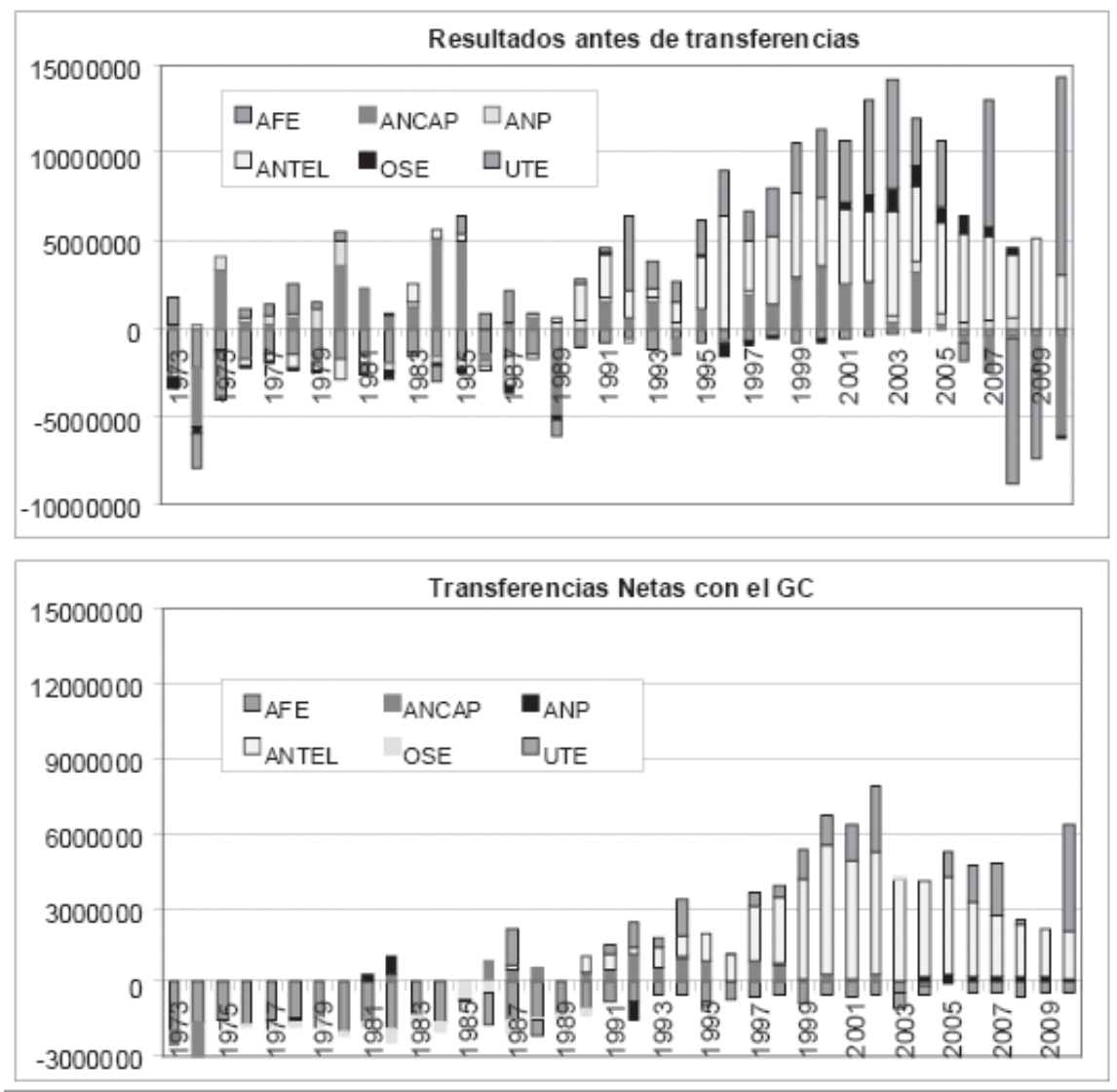

Fuente: OPP.

Nuevamente en este período existieron momentos particulares de necesidades fiscales donde se recurrió a las empresas públicas. Así, incluso en el marco de los difíciles años pos crisis de 1982, se solicitó contribuciones a ANP y ANCAP. Asimismo, las contribuciones de las EPNF5 fueron crecientes aunque no muy elevadas en momentos en que se implementaba un plan de estabilización al inicio de los noventa. Muy significativos y crecientes fueron sus aportes durante la recesión de fines de los noventa y durante la crisis de 2002. La situación durante la crisis internacional de 2008-2009 fue distinta, dado que las empresas públicas no financieras redujeron sus contribuciones y sus aportes totales (contribuciones más el resultado después de ellas) fueron negativos, en buena medida debido a que sus tarifas se gestionaron buscando no presionar sobre la inflación, principal escollo de la política económica del momento. No obstante, en 
paralelo, los bancos públicos superavitarios (BROU y BSE) aportaron de forma creciente al fisco en esos años, contrarrestando así la caída de las contribuciones de las empresas públicas no financieras.

\section{CONCLUSIONES}

Las empresas públicas uruguayas recorrieron desde los setenta un camino de reformas similar, si bien quizás más gradualista, al de otros países de AL que en los noventa privatizaron sus empresas. Se reperfilaron los objetivos de las empresas dándole más relevancia a la eficiencia económica y a la rentabilidad, y se avanzó hacia tarifas más realistas y en la reducción de los subsidios, entre otros aspectos. Desde la dictadura de alguna forma se redefinió el tamańo del sector público y se fueron desregulando sectores de actuación y eliminando todas aquellas actividades y empresas que no eran consideradas estratégicas.

Estos cambios alineados con el modelo liberal se hicieron sin llegar a la privatización de ninguna de las empresas públicas no financieras estudiadas, las que forman (junto a los tres bancos públicos que tampoco fueron privatizados) el núcleo duro del Estado empresario uruguayo. Cabe preguntarse las razones de este comportamiento peculiar. El estudio de la trayectoria y el desempeño de las empresas deja algunas pistas. Estas empresas se han caracterizado por su pequeño número, su gran tamaño en relación a la dimensión de la economía del país y su notoria estabilidad y antigüedad. A diferencia de lo sucedido en varios países europeos y latinoamericanos, las empresas públicas uruguayas se han centrado en la prestación de servicios públicos, en general con carácter monopólico. No se ha incursionado en una dimensión significativa, con la salvedad de ANCAP, en la producción industrial, lo que podría explicarse por la debilidad del proceso de industrialización en Uruguay, que no logró pasar a la segunda fase de la ISI, caracterizada por la instalación de las industrias básicas. Otra característica de gran importancia es que, en general, no han sido fuertemente deficitarias, salvo el caso de los ferrocarriles.

También se ha podido observar la fortaleza de la impronta estatista en la sociedad uruguaya, como muestran la resistencia popular a las privatizaciones y la debilidad del impulso privatizador en los setenta y ochenta, incluso en el seno del gobierno autoritario. La existencia de una "matriz de lo público profundamente estatista", para decirlo en palabras de Gerardo Caetano ${ }^{16}$.

I6 En comunicación presentada en el Simposio sobre Empresas Públicas, realizado en ANTEL los días 29 a 3 I de octubre de 20 I 2 , reproducido en página web de ANTEL. 
La interpretación de los resultados confirma de alguna manera la caracterización del período realizada previamente respecto a la existencia de dos grandes modelos, y de determinadas subetapas. Las cuatro oleadas de creación de empresas públicas marcan las distintas subetapas del primer modelo de empresas públicas que se extenderá hasta el inicio de los setenta, caracterizado por el avance del accionar estatal en general y del Estado empresario en particular, en línea con lo ocurrido a nivel internacional.

La primera oleada que da inicio a la etapa de surgimiento y consolidación de las empresas públicas, fue la creación de las primeras empresas públicas alrededor del inicio del siglo XX. Luego, una segunda oleada terminó de conformar el núcleo principal de las empresas públicas no financieras durante los ańos iniciales de la década del treinta. En la etapa de apogeo del Estado empresario se crean otras importantes empresas públicas no financieras, nacionalizaciones de empresas británicas. Finalmente, la cuarta ola de creación de empresas públicas no financieras -conceptualizadas en sentido amplio- responde al "salvataje u hospital de empresas", en el marco de una economía estancada y con desempleo como la de los sesenta.

Las variables de desempeño consideradas para las EPNF5 uruguayas, reflejan en general dichos momentos. Existió un empleo creciente en número de funcionarios y peso en la PEA hasta fines de los sesenta, con una aceleración durante la etapa de apogeo de las empresas públicas. Asimismo, se encuentran niveles de producción que muestran una aceleración en la postguerra tanto si se consideran las nuevas empresas nacionalizadas (AFE y OSE) como si no. Sin embargo, mostrarán los impactos del estancamiento económico durante los sesenta.

En términos de productividad, en los treinta con la instalación de ANCAP se produce un fuerte incremento de la producción y de la productividad. Pero luego la expansión de actividades muy intensivas en empleo, en particular en ANCAP, y la incorporación de AFE con similar característica durante los ańos cincuenta, impidieron un crecimiento significativo de la productividad pese al incremento de la producción en el marco de un importante crecimiento económico en el país. En los sesenta la expansión del empleo contrastó con la evolución de la producción agregada de las EPNF5, conllevando a la caída de la productividad y cerrando la etapa global del auge del Estado empresario con estancamiento de la misma, así como moderando el incremento de la participación del valor agregado de estas empresas en el PIB.

Acompañando en líneas generales esta evolución, en la primera mitad del siglo existen utilidades positivas y contribuciones al fisco, luego los resultados se deterioran y las empresas públicas no financieras se 
transforman en un costo para el gobierno, debido principalmente al déficit permanente de AFE.

Desde los setenta, bajo la denominada etapa liberal, la productividad tuvo un fuerte crecimiento. Primero siguiendo el aumento de producción, en un marco de no caída del empleo en el conjunto de las EPNF5 a diferencia de lo ocurrido en otros países de América Latina (Del Campo y Winkler 1992). En los noventa creció por la fuerte reducción del empleo $y$, en los últimos ańos, el moderado incremento de la productividad parece responder nuevamente a aumentos en la producción. Los resultados mejoraron notablemente, siendo las EPNF5 importantes contribuyentes al fisco durante las dos últimas décadas.

Finalmente, es de interés mencionar que las EPNF5 han aumentado su participación en el PIB prácticamente de forma continua a lo largo de su siglo de existencia, con períodos de mayor crecimiento durante la etapa de apogeo del Estado empresario y en los noventa. De esta forma, en el marco de la ideología liberal del segundo modelo, encontramos una reducción del tamaño del Estado a partir de la medición del empleo, pero no a partir de su contribución al producto nacional.

En definitiva, Uruguay no fue ajeno ni la excepción al proceso de reformas de las empresas públicas desde los setenta en buena parte del mundo. Y ello tanto antes como después del párate a la ola privatizadora de inicio de los noventa. En la etapa previa, siguió los pasos generales del proceso de reforma de otros países de la región, y desde los noventa ha llevado adelante un camino particular de reforma de los sectores de actuación de las empresas públicas no financieras y de ellas mismas, que podríamos denominar de "caso a caso".

Si bien el impulso liberal no logró en Uruguay la privatización de sus grandes empresas públicas no financieras, sí redujo muy fuertemente su personal -mucho más que en el resto del sector público-, y llevó adelante importantes procesos de desregulación y tercerización y concesión de servicios, al tiempo que buena parte de la expansión de actividades de las empresas se ha realizado bajo la modalidad de fundación de sociedades anónimas de propiedad pública, algo que rompió con la tradición histórica de empresas públicas de derecho público en el país.

Por último, aunque es un ámbito que debe profundizarse, puede señalarse que en los últimos años, los gobiernos progresistas han llevado adelante experiencias tanto de continuidad como de ruptura con dichas tendencias. 


\section{REFERENCIAS}

Acevedo, E. (1919-1936). Anales Históricos del Uruguay. Montevideo: Editorial Barreiro y Ramos.

Azar, P., Bertino, M., Bertoni, R., Fleitas, S., García Repetto, U., Sanguinetti, C., Sienra, M. y Torrelli, M. (2009). ¿De Quiénes, para Quiénes y para Qué? Las Finanzas Públicas de Uruguay en el Siglo XX. Montevideo: Editorial Fin de Siglo.

Belini, C. y Rougier, M. (2008). El Estado Empresario en la Industria Argentina. Conformación y Crisis. Buenos Aires: Editorial Manantial.

Bertino, M., Mariño, N., Torrelli, M. y Vazquez, D. (2012a). Las Empresas Públicas Uruguayas en el Largo Plazo y sus Vínculos con la Política Económica. Ponencia presentada en el 54 Congreso de Americanistas, 15 al 20 de julio, Viena.

(2012b). Desempeño Productivo de las Empresas Públicas No Financieras Uruguayas en el Largo Plazo. Ponencia presentada en el III Congreso Latinoamericano de Historia Económica, 23 al 27 de octubre, Bariloche.

- (2012c). Fijación de tarifas públicas y su vinculación con la política económica en Uruguay (1912-2010). Ponencia presentada en el III Congreso Latinoamericano de Historia Económica, 23 al 27 de octubre, Bariloche.

- (2012d). Historia de una Empresa Pública Uruguaya: 60 años de Obras Sanitarias del Estado (OSE). Ponencia presentada en el III Congreso Latinoamericano de Historia Económica, 23 al 27 de octubre, Bariloche.

Bertino, M., Rímoli, P., Torrelli, M. y Vázquez, D. (2011). Contribuciones versus Subsidios: Acerca de los Vínculos Financieros entre las Empresas Públicas Uruguayas y el Gobierno Central. Ponencia presentada en el III Jornadas de Historia de la Industria y los Servicios, Facultad de Economía, UBA, 31 de julio al 2 de agosto, Buenos Aires.

Bertino, M. y Tajam, H. (1999). El PBI de Uruguay: 1900-1955. Montevideo: Editorial Prisma. 
Boneo, H. (1973). Las Empresas Públicas Industriales y Comerciales en el Uruguay. Montevideo: Presidencia de la República, Oficina Nacional del Servicio Civil.

Carracelas, G., Ceni, R. y Torrelli, M. (2006). Las Tarifas Públicas bajo un Enfoque Integrado. Monografía Final de Licenciatura (Economía), Facultad de Ciencias Económicas y de Administración, Universidad de La República, Uruguay.

Comín, F. y Díaz Fuentes, D. (2004). La Empresa Pública en Europa. Una Perspectiva Histórica. Madrid: Editorial Síntesis.

Del Campo, A. y Winkler, D. (1992). Reforma de las empresas públicas latinoamericanas. Revista de la CEPAL, 46, 53-76.

Dondo, P. (1940). Los Ciclos en la Economía Nacional. Monografía Final de Licenciatura (Economía), Facultad de Ciencias Económicas y de Administración, Universidad de La República, Uruguay.

Millward, R. (2005). Private and Public Enterprise in Europe: Energy, Telecommunications and Transport, 1830-1990. Cambridge: Cambridge University Press.

Milnitsky, S. (2001). Empresas y Servicio Públicos: ¿A qué Estamos Jugando? En Proyecto Agenda Uruguay (Ed.), Servicios públicos: aportes hacia una politica de Estado. Montevideo: Trilce.

Nahum, B. (1993). Empresas Públicas en el Uruguay. Origen y Gestión. Montevideo: Banda Oriental.

Nahum, B., Bertoni, R., Galán, L., Harriet, S. y Pellegrino, I. (2006). Lo Que Nos Mueve es Todo un País 1931-2006. ANCAP. Montevideo: Editorial ANCAP.

Narbondo, P. (2012). Las Reformas de la Matriz de Funciones Socioeconómicas y de la Estructura Organizativa Del Estado y el Sector Público en los Gobiernos del Frente Amplio. Montevideo: Mimeo.

Piotti, D. (1997). Historia de las Telecomunicaciones en el Uruguay. Montevideo: Ediciones de la Guía Financiera. 
Rodríguez López, J. (1928). Socialismo en el Uruguay. La Gestión Económica del Estado. Montevideo: Editorial Palacio del Libro.

Solari, A. y Franco, R. (1983). Las Empresas Públicas en Uruguay: Ideología y Política. Montevideo: Fondo de Cultura Universitaria.

Recibido: 22-11-2012

Aceptación de la versión final: 25-03-2013 